in press at Journal of Experimental Psychology: General

\title{
How development and culture shape intuitions about prosocial obligations
}

\author{
Julia Marshall ${ }^{1,2}$, Anton Gollwitzer ${ }^{1}$, Kellen Mermin-Bunnell ${ }^{1}$, Mei Shinomiya ${ }^{1}$, Jan Retelsdorf ${ }^{3}$, \\ Paul Bloom ${ }^{1}$ \\ ${ }^{1}$ Yale University; ${ }^{2}$ Boston College, ${ }^{3}$ University of Hamburg
}

\begin{abstract}
Do children, like most adults, believe that only kin and close others are obligated to help one another? In two studies (total $N=1140)$, we examined whether children ( $\sim 5$ - to $\sim 10$-yos) and adults across five different societies consider social relationship when ascribing prosocial obligations. Contrary to the view that such discriminations are a natural default in human reasoning, younger children in the United States (Studies 1 and 2) and across cultures (Study 2) generally judged everyone - parents, friends, and strangers - as obligated to help someone-inneed. Older children and adults, on the other hand, tended to exhibit more discriminant judgments. They considered parents more obligated to help than friends followed by strangers - though this effect was stronger in some cultures than others. Our findings suggest that children's initial sense of prosocial obligation in social-relational contexts starts out broad and generally becomes more selective over the course of development.
\end{abstract}

Keywords: psychology, morality, development, prosocial, cross-cultural

(C) 2022, American Psychological Association. This paper is not the copy of record and may not exactly replicate the final, authoritative version of the article. Please do not copy or cite without authors' permission. The final article will be available, upon publication, via its DOI: DOI: $\underline{10.1037 / \mathrm{xge} 0001136}$ 


\section{Introduction}

Most people believe that close others, including family and friends, are obligated to help one another (Haidt \& Baron, 1996; Marshall, Wynn, \& Bloom, 2020; McManus, Kleiman-Weiner, \& Young, 2020; Miller, Bersoff, \& Harwood, 1990). To provide help to unknown others, in contrast, is often seen as supererogatory-going above and beyond the call of duty (Aquinas, 1948). For instance, parents who help their children by providing them with food and shelter are not seen as morally exemplary - they are doing the right thing. But to feed and house a homeless stranger would be seen as morally exceptional, perhaps even saintly.

Some philosophers have argued that this is a morally good distinction to make; we really do have special obligations to support friends and family members, and these do not typically extend to strangers (e.g., Jeske, 1998; Narveson, 2017; Sommers, 1986). Others, however, argue that we would be better off as fairer and more impartial (e.g., Singer, 1981); we should not consider ourselves especially tied to close others but should instead recognize that we have obligations to all people-indeed, to all sentient beings. From this perspective, moral progress reflects the expansion of our sense of obligation. As Peter Singer (1981, p. 120) notes, "The circle of altruism has broadened from the family and tribe to the nation and race, and we are beginning to recognize that our obligations extend to all human beings."

Regardless of which perspective is morally defensible, philosophers engaged in these discussions tend to share the assumption that we, as humans, feel a special obligation to help close others. Indeed, many psychologists have argued that this is part of our very nature (e.g., Bloom, 2013; Wynn et al., 2018). There are evolutionary forces, after all, driving us to behave altruistically - and perhaps driving us to believe that one should behave altruistically - towards some individuals and not others. For instance, kin selection favors individuals who favor their genetic relatives over strangers (e.g., Dawkins, 1989). Additionally, reciprocal altruism-a motivation to help those who have helped us in the past-promotes cooperation among close others given they are more likely to interact with one another in the future (e.g., Axelrod, 1987). From this perspective, it is hard to see the evolutionary payoff of a felt obligation to strangers. Expanding on this point, Richard Dawkins wrote, "Be warned that if you wish, as I do, to build a society in which individuals cooperate generously and unselfishly towards a common good, you can expect little help from biological nature" (Dawkins, 1989, pp. 3-4).

But is it true that our sense of obligation is naturally restricted to only close others? While there has been considerable research into how children's sharing and giving behavior is influenced by social relationships (e.g., Engelmann, Zhang, Zeidler, Dunham, \& Herrmann, 2021; Olson \& Spelke, 2008), there has been surprisingly little corresponding research into either children's or adults' judgments of prosocial obligation (Tomasello, 2020) - the focus of the present research. Given that moral behaviors and judgments often diverge (Blake, McAuliffe, \& Warneken, 2014; $\mathrm{Yu}$, Siegel, \& Crockett, 2020), we do not yet know whether children actually start off conceptualizing prosocial obligations as restricted to close others and only later broaden their moral circles (i.e., narrow-to-broad), or whether they begin with an indiscriminate morality and, through development, come to judge only certain individuals as obligated to help one another (i.e., broad-to-narrow). The present study aims to investigate which of these possibilities best characterizes children's reasoning about prosocial obligation. 
We know quite a bit about adults' obligation judgments. Adults, at least in the United States, consider an unhelpful family member as more morally wrong than an unhelpful stranger (Haidt \& Baron, 1996). In addition to these evaluation judgments, adults in the United States also judge individuals who fail to help family members as violating an obligation more so than individuals who fail to help strangers (McManus et al., 2020; McManus, Mason, \& Young, 2021). Interestingly, however, research with college-aged students in India found that they-unlike adults in the United States - do not appear to care as much about social relationships; instead, they consider parents, friends, and strangers as equally obligated to help a person-in-need (Miller et al., 1990).

What about children? In line with adult work, children in the United States as young as seven tend to take social relationship into account when judging third-parties - they evaluate unhelpful friends as meaner than unhelpful strangers (Marshall et al., 2020) and also consider friends more obligated to help than strangers (Miller et al., 1990). Like Indian adults, though, children as young as seven in India do not appear to care as much about such social relationships (Miller et al., 1990), suggesting cultural variability is present in obligation judgments by age seven.

With respect to younger children, we know even less. Some recent research finds that 3- to 5 -year-olds in the USA-like older children in India-consider helping obligatory regardless of social-relational context (e.g., parent and acquaintance; Dahl, Gross, \& Seifert, 2020). Alternatively, recent work by Mammen and colleagues (2021) finds that 4- and 6-year-olds in Germany consider parents more likely to help than friends and tend to use more normative language ('have to') to justify help on behalf of parents compared to friends. Supporting the notion that younger children take social relationships into account, research by Paulus and colleagues (2020) finds that 4- to 6-year-olds evaluate someone who helps a friend more positively than someone who helps a disliked other.

Collectively, these studies point toward the possibility that development and culture both play a role in shaping a mature sense of obligation. To explore this question directly, however, it is critical to test children across a large age range to generate a developmental picture of how children vary in their reasoning about social-relational obligations across middle childhood. Additionally, it is important to test children from a wide array of culturally diverse societies to better generate an understanding of how cultural context shapes children's reasoning similarly or differently across cultural contexts (Amir \& McAuliffe, 2020; Nielsen \& Haun, 2016; Nielsen, Haun, Kartner, \& Legare, 2017). The present studies do just this by conducting a developmental and cross-cultural investigation into how children's and adults' sense of prosocial obligation develops.

In Study 1, we tested children in the United States as young as 5 years of age and as old as 9 years of age as to better characterize the developmental trajectory of children's sense of prosocial obligation. In Study 2, we extended these findings by recruiting participants from divergent societies, including Western and non-Western cultures: Germany, India, Japan, Uganda, United States. Taken together, these studies can answer a number of related questions. First, do children reason more broadly or more narrowly about prosocial obligations? Second, does this pattern of reasoning vary as a function of culture and development? The answer to these questions bears on 
whether humans are naturally inclined to judge prosocial obligations as restricted to close others (e.g., Singer, 1981) and whether culture plays a role in these judgments across development.

\section{Study 1}

In Study 1, we investigate whether children in the United States tend to judge individuals as only obligated to close others, such as family members and friends, or whether they extend obligations to distant others, such as strangers. In line with previous research (McManus et al., 2020), we measured prosocial obligation in two ways - directly asking participants (a) whether a potential helper (parent, friend, stranger) has to help and (b) whether this potential helper is mean for not helping. In this way, we can assess how children reason about prosocial obligations across social-relational contexts.

\subsection{Method}

\subsubsection{Participants}

We tested 102 children ranging from 5 years of age to 9 years of age. We aimed to test approximately 20 children per the smallest unit of analysis - which in this case was categorical age - who passed our comprehension checks. This resulted in a planned sample of 100 children. We stopped testing children on the day in which the last child was tested using this criterion, resulting in 102 total children. A sensitivity analyses of our final sample revealed that we had $95 \%$ power to find a small to medium effect size ( $f=.36$ or higher). This study was not pre-registered.

Twenty-nine of the children were tested in a lab at Yale University, and 73 were tested at a local natural history museum. The study was run identically across testing locations. The majority of the sample (64.7\%) was White. The remaining were Asian (15.7\%), Black (10.8\%), Hispanic $(6.9 \%)$, or Other $(2 \%)$. We also tested seven additional children but excluded them for failing comprehension checks (which are described in detail below); including these participants in the analyses did not meaningfully change the results.

We also tested adult participants on Amazon Mechanical Turk (MTurk). We aimed for a final sample of 20 adults to match the number of children recruited per categorical age and therefore tested 40 participants on MTurk to account for comprehension failures. Fifteen participants failed comprehension checks and were excluded (the findings do not change if we include all participants). The final sample thus included 25 adults (9 females) and was predominately White $(n=22){ }^{1}$

\subsubsection{Procedures and materials}

An experimenter introduced child participants to two stories in counter-balanced order; adult participants read identical materials online. All verbatim materials are available in the

\footnotetext{
${ }^{1}$ Though this adult sample size was small, we observed consistent effects with a larger sample in Study 2.
} 
Supplemental Online Material (SOM). The stories either featured a child who was at a playground (henceforth, playground story) or a child who was at a fair (henceforth, fair story). We selected these two story-types because we thought they represented cases where someone was moderately in need of help (see Miller et al., 1990).

For the playground story, an experimenter presented child participants with an image of a child at a fair named Brian (the protagonist) surrounded by three witnesses: the protagonist's father, the protagonist's friend, and a person the protagonist did not know at all (i.e., a stranger). We described the stranger as someone who the protagonist did not know at all as to avoid using the term "stranger," which may have negative connotations (think, "stranger danger"). The experimenter pointed to each of these witnesses and verified participants could identify each one. If a participant responded incorrectly, they were corrected and asked again. If a participant persisted in responding incorrectly after two corrections, the participant was excluded for failing comprehension checks $\left(n_{\text {child }}=7 ; n_{\text {adult }}=15\right)$. Next, the experimenter said: "Let's say that one day Brian was at a fair, and Brian didn't have any food, so he was very hungry. Brian's dad, Brian's friend, and the person Brian doesn't know see that Brian is hungry."

For the fair story, which paralleled the playground story, an experimenter presented child participants with an image of a child at a playground named Megan (the protagonist) surrounded by three witnesses: the protagonist's mother, the protagonist's friend, and a person the protagonist did not know at all (i.e., a stranger). Like for the playground story, an experimenter verified that participants could identify each of the witnesses and corrected incorrect participants if necessary. Next, the experimenter said, 'Let's say that one day Megan was at the park, and Megan fell down and hurt herself, so she was very sad. Megan's mom, Megan's friend, and the person Megan doesn't know at all see that Megan is hurt."

For each story type, the experimenter first asked three expectation questions. For example, the experimenter asked, "Do you think Brian's dad will help Brian? Yes or no?". We included this item for two reasons. First, we aimed to replicate previous research by Marshall et al. (2020). ${ }^{2}$ Second, we considered the possibility that variation in participants' obligation judgments may result from variation in participants' expectations, as previous research would indicate (MendeSiedlecki, Baron, \& Todorov, 2013). As a result, expectation judgments were not a key variable of interest, as they did not measure obligation, but were included as a control measure.

Next, we asked participants three obligation questions in randomized order. ${ }^{3}$ For example, the experimenter asked, "Do you think Brian's dad has to help Brian? Yes or no?" in addition to

\footnotetext{
2 Because of this aim, we ultimately decided to leave expectation judgments in binary form and not ask the followup questions (e.g., a tiny bit, a little bit, a lot), as was done for obligation judgments. In Marshall et al. (2020), expectations questions were asked in a binary format. In Study 2, expectations were asked in an identical format as obligations (i.e., with a continuous follow-up scale).

3 We included a "training phase" where we asked participants obligation questions prior to the main questions. Specifically, we told participants, "Sometimes people have to do things. When a teacher tells you to stop being mean, do you have to stop being mean? Yes or no?" (correct answer: yes) followed by, "how much do you think you have to stop being mean?". Additionally, we asked, "When someone asks you a question, do you have to lie?" Yes or no?" (correct answer: no) followed by, "how much do you think you have to lie?" We did not include this training in Study 2 (where we find the same results) because we wanted to ensure we were not "teaching participants to the test."
} 
"How much do you think he has to? A teeny bit, a little bit, or a lot?", if participants responded "yes". This resulted in a 4-point obligation scale for each witness for each story type $(1=$ No, $2=$ Yes, a tiny bit, 3 = Yes, a little bit, $4=$ Yes, a lot). We decided to utilize the language "have to" as previous research has documented that children distinguish between what individuals have to do, prefer to do, and usually do (Kalish \& Lawson, 2008; Mammen et al., 2021). In this way, this item is closest to conceptually measuring children's sense of obligation.

Afterward, the experimenter then revealed that none of the potential helpers helped the person-in-need. For example, the experimenter would say, "Now let's say that Brian's dad, Brian's friend, and the person Brian didn't know at all do not help Brian." The experimenter then asked three follow-up sets of questions. Each follow-up set involved two questions - a comprehension check and then the evaluation question. For instance, the experimenter would ask, "Did Brian's dad help Brian? Yes or no?" If the participant responded incorrectly, the experimenter corrected the participant and asked again. If the participant continued to respond incorrectly, the participant was excluded for inattention. The experimenter then asked the individual evaluation question: "Was he mean or not mean?" followed by "How mean do you think he was? A teeny bit mean, a little bit mean, or very mean?", if the participant responded "mean" (4-point scale). We included this evaluation item as others have found similar results between obligation and evaluation measures (McManus et al., 2020, 2021).

We included two other additional items for exploratory purposes. First, we measured children's overall evaluation of the situation (Supplemental Figure 1), which ensured children found not helping in general bad. Second, we included a set of forced choice questions (Supplemental Figure 2), which required participants to select who is meaner between (a) the unhelpful parent and unhelpful friend, (b) unhelpful parent and unhelpful stranger, (c) unhelpful friend and unhelpful stranger. We did so to replicate previous research by Marshall et al. (2020). These results are presented in the SOM because they are not the focus of the current work and because the findings cohered with past as well as the presented results.

\subsection{Results}

\subsubsection{Obligation judgments}

Using the lme4 package (Bates, Sarkar, Bates, \& Matrix, 2007), we examined children's obligation judgments. Specifically, we created linear mixed-effects models with participant ID included as a random intercept to account for individual variability across participants. Three separate models were created and compared. Model 1 included the main effects of Age (continuous; centered around zero), Social Relationship (parent, friend, stranger; withinparticipants), and Scenario (fair, playground; within-participants). Model 2 added all the two-way interactions amongst these variables. Model 3 added the single three-way interaction amongst these variables. Model comparisons were calculated via likelihood ratio tests.

Model 2, which included all two-way interactions between Age, Social Relationship, and Scenario, exhibited improved model fit compared to Model 1, which included only the main effects; $\chi^{2}=24.17, p<.001$. Model 3, which include the three-way interaction (and all lower-order terms), however, did not improve model fit compared to Model $2 ; \chi^{2}=.56, p=.756$. Indeed, the 
three-way interaction between Age, Social Relationship, and Scenario in Model 3 was not significant, $F(2,500)=.27, p=.760$. As such, the following analyses were conducted with Model $2\left(R_{\text {conditional }}^{2}=.59 ; R_{\text {marginal }}^{2}=.18\right)$. For detailed analyses, see RMarkdown on OSF for full code, summary outputs, and additional information. Additionally, on the whole, we do not find many effects of Scenario in the studies presented here, but information about such effects can be found in the RMarkdown file.

Most relevant to the question of how children reason about social-relational obligations, Model 2 revealed a significant interaction between Social Relationship and Age, $F(2,502)=10.88$, $p<.001$. The other two-way interactions in the model-Age $\mathrm{x}$ Scenario and Social Relationship $\mathrm{x}$ Scenario-were not significant $(p s>.134)$. The observed interaction between Social Relationship and Age revealed a developmental shift in obligation judgments (Figure 1). To best understand this, we unpacked this interaction in two ways. First, we examined the effect of Social Relationship at older and younger ages on obligation judgments. Second, we examined the simple slopes of Age on obligation judgments for each social relationship.

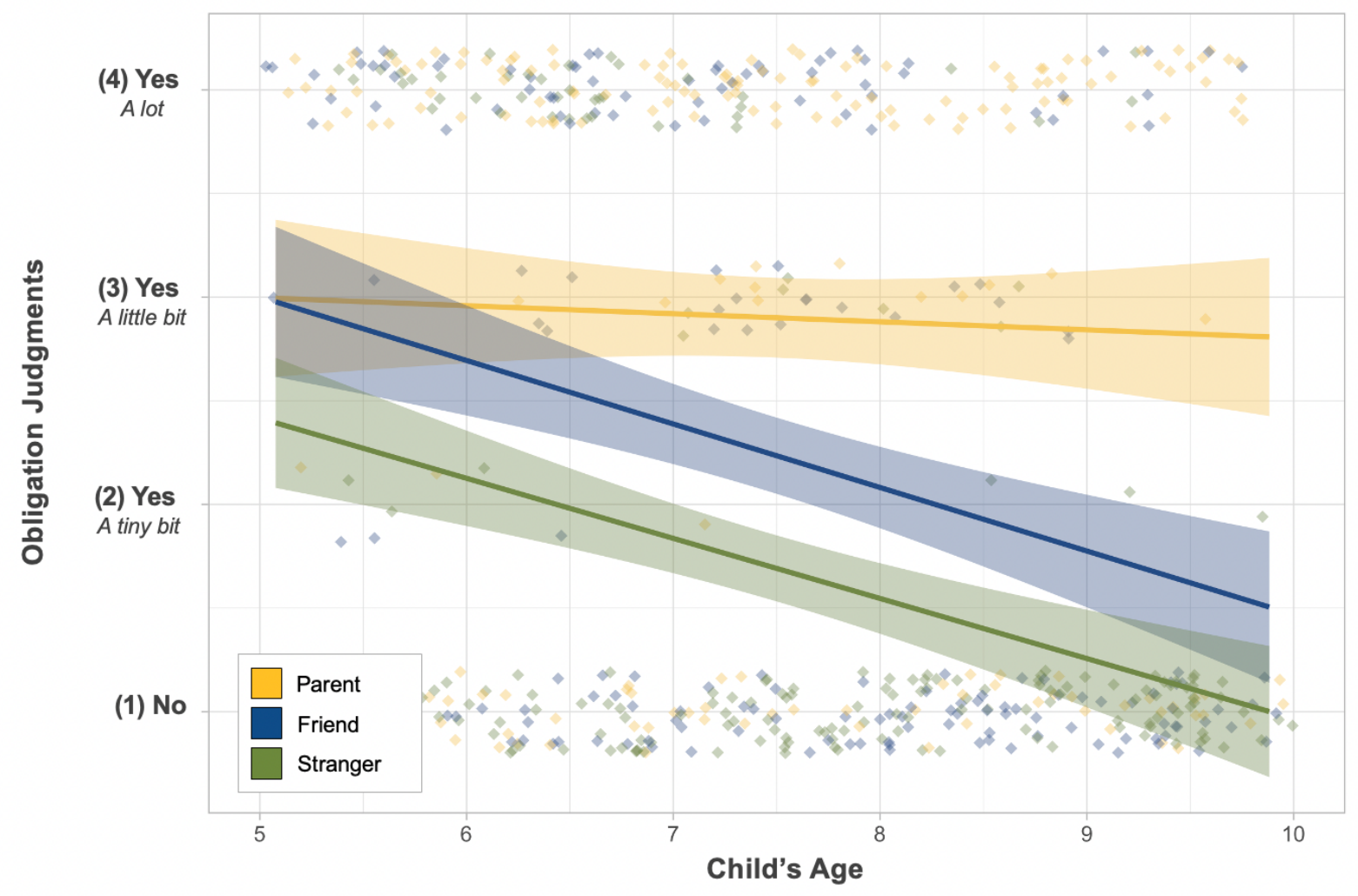

Figure 1 | Child participants' obligation judgments as a function of Social Relationship (parent, friend, stranger) and Age (continuous). Error bars represents \pm one $S E$.

The former analysis revealed that-although younger children (-1.5 $S D$; Age: 5.35) exhibited some discrimination on the basis of social relationship, $F(2,502)=7.30, p<.001-$ their obligation judgments were considerably less discriminate than older children's judgments. 
Specifically, older children (1.5 SD; Age: 9.58) exhibited discriminate judgments, $F(2,502)=$ $46.39, p<.001$, judging parents as most obligated to help followed by friends and then strangers (Table 1). In line with these results, our trend analyses revealed that - as illustrated in Figure 1age did not correlate with parent obligation judgments, $B=-0.04, S E=0.08,95 \%$ CI [-0.20, 0.19]; $t=-0.49, p=.625$. It did, however, correlate negatively with friend obligation judgments, $B=-$ $0.31, S E=0.08,95 \% \mathrm{CI}[-0.46,-0.15] ; t=-3.86, p<.001$, and negatively with stranger obligation judgments, $B=-0.29$, $S E=0.08,95 \%$ CI $[-0.45,-0.13] ; t=-3.65, p<.001$. In summary, younger children were more inclined to judge parents, friends, and strangers as obligated to help one another in comparison to older children, who generally only considered parents obligated to help.

Table 1. Means, standard errors, pairwise comparisons, effect sizes, and effect size confidence intervals for comparisons within younger and older children for obligation judgments. $\diamond$ indicate the pairwise comparison in question.

\begin{tabular}{|c|c|c|c|c|}
\hline & Parent & Friend & Stranger & Significance Test \\
\hline \multirow{4}{*}{$\begin{array}{l}\text { Younger Children } \\
\text { (-1.5 SD; Age: } 5.35)\end{array}$} & $\begin{array}{l}2.98 \\
(.20)\end{array}$ & $\begin{array}{l}2.89 \\
(.20)\end{array}$ & $\begin{array}{l}2.31 \\
(.20)\end{array}$ & $F(2,502)=7.30, p<.001$ \\
\hline & $\diamond$ & $\diamond$ & & $B=0.09, S E=.16, t=.56, p=.841 ; 95 \% \mathrm{CI}[-0.29,0.48]$ \\
\hline & $\diamond$ & & $\diamond$ & $B=0.67, S E=.16, t=4.11, p<.001 ; 95 \%$ CI $[0.29,1.05]$ \\
\hline & & $\diamond$ & $\diamond$ & $B=0.58, S E=.16, t=3.55, p=.001 ; 95 \%$ CI $[0.20,0.96]$ \\
\hline \multirow{4}{*}{$\begin{array}{c}\text { Older Children } \\
\text { (1.5 SD; Age: } 9.59)\end{array}$} & $\begin{array}{l}2.82 \\
(.20)\end{array}$ & $\begin{array}{l}1.60 \\
(.29)\end{array}$ & $\begin{array}{l}1.09 \\
(.20)\end{array}$ & $F(2,502)=46.39, p<.001$ \\
\hline & $\diamond$ & $\diamond$ & & $B=1.22, S E=.16, t=7.49, p<.001 ; 95 \%$ CI $[.84,1.61]$ \\
\hline & $\diamond$ & & $\diamond$ & $B=1.73, S E=.16, t=10.61, p<.001 ; 95 \%$ CI $[1.35,2.12]$ \\
\hline & & $\diamond$ & $\diamond$ & $B=0.51, S E=.16, t=3.12, p=.005 ; 95 \%$ CI $[0.13,0.89]$ \\
\hline \multirow{4}{*}{ Adults } & $\begin{array}{l}3.44 \\
(.22)\end{array}$ & $\begin{array}{l}1.98 \\
(.22)\end{array}$ & $\begin{array}{l}1.04 \\
(.22)\end{array}$ & $F(2,122)=97.07, p<.001$ \\
\hline & $\diamond$ & $\diamond$ & & $B=1.46, S E=.18, t=8.13, p<.001 ; 95 \%$ CI $[1.04,1.88]$ \\
\hline & $\diamond$ & & $\diamond$ & $B=2.40, S E=.18, t=13.37, p<.001 ; 95 \%$ CI $[1.98,2.82]$ \\
\hline & & $\diamond$ & $\diamond$ & $B=0.94, S E=.18, t=5.24, p<.001 ; 95 \%$ CI $[0.52,1.36]$ \\
\hline
\end{tabular}

We conducted three subsidiary analyses. First, we considered the possibility that the documented developmental effects may be driven by how children respond to Likert-style scales. Perhaps younger children simply respond more extremely than older children. To rule out this possibility, we transformed the Likert-style obligation measure into a binary variable $(1=$ yes, $0=$ no). When doing so, we found the same results as reported above in that Model 2 exhibited improved fit over Model 1, $\chi^{2}=18.30, p=.003$, and Model 3 did not improve model fit, $\chi^{2}=.15$, 
$p=.930$. Importantly, we again found the observed Social Relationship $\mathrm{x}$ Age interaction, $\chi^{2}=$ 14.41, $p<.001$ (Supplemental Figure 3; see RMarkDown file on OSF for simple effects).

Second, we considered the possibility that children's variation in obligation judgments as a function of social relationship and age may emerge because of variation in whether children expect actors to help. For example, perhaps younger children consider strangers more obligated to help because they think strangers are more likely to help one another than older children do. To address this possibility, we conducted two analyses. First, we examined whether the Social Relationship $\mathrm{x}$ Age found for obligation judgments also emerges for expectation judgments ${ }^{4}$. To do so, we reconducted the three main models but with expectations as the outcome variable. We found that - unlike for obligations - the three models did not differ from one another in terms of fit $\left(1.34<\chi^{2} \mathrm{~s}<7.05 ; .217<p \mathrm{~s}<.512\right)$. These results indicate that, when predicting children's expectation judgments, a model including the interaction between Social Relationship and Age does not add explanatory power compared to a model that only includes the main effects of the variables of interest. In line with this conclusion, an interaction between Social Relationship and Age was not observed, $\chi^{2}=3.68, p=.159$ (Supplemental Figure 4). Second, we also examined whether the Social Relationship x Age interaction observed for obligation judgments in Model 2 remained when including expectation judgments as a control (as a main effect and all possible two-way interactions) in the model. Notably, we found that the key interaction predicting obligation judgments remained when doing so, $\chi^{2}=11.81, p=.003$.

Third, we compared younger and older children's responses to adults' responses. To do so, we ran the same analyses as above but changed age to a categorical variable (Age Group) with three levels: younger children, older children, and adults (younger and older children was categorized via a median split). When doing so, we again found that Model 2 exhibited improved fit over Model 1, $\chi^{2}=70.58, p<.001$, and Model 3 did not improve Model fit, $\chi^{2}=1.23, p=.874$. Importantly, we also again observed that the Social Relationship x Age interaction predicted obligation judgments, $F(4,619)=17.75, p<.001$ (Supplemental Figure 5). Regarding simple effects, and in line with our earlier findings, we did not find an effect of Age Group for parent obligation judgments, $F(2,124)=1.93, p=.150$. We did, however, find an effect of Age Group for friend obligation judgments, $F(2,124)=5.61, p=.005$, and stranger obligation judgments, $F(2,124)=16.46, p<.001$. Echoing our earlier findings, younger children judged friends and strangers as more obligated to help than older children and adults did (see RMarkDown file on OSF for detailed analyses).

\subsubsection{Evaluation judgments}

In line with past research having observed links between obligation and evaluation judgments (McManus et al., 2020), we next examined whether children's evaluations of unhelpful others followed a similar pattern. To do so, we conducted the identical set of analyses as we did for prosocial obligations but instead for evaluations of unhelpful others. Akin to obligations, Model 2, which included all two-way interactions between Social Relationship, Age, and Scenario, exhibited improved model fit compared to Model 1, which included only the main effects; $\chi^{2}=$ 41.22, $p<.001$. Model 3, which include the three-way interaction did not improve model fit

\footnotetext{
${ }^{4}$ Note that we examined participants' obligation judgments in binary form (yes, no) because - for reasons described in the 'Methodology' - participants' expectation judgments measured only in binary form.
} 
compared to Model 2; $\chi^{2}=.009, p=.995$. Indeed, the three-way interaction between Social Relationship, Age, and Scenario in Model 3 was not significant, $F(2,500)<.01, p=.995$. As such, and as was the case for obligations, we unpacked Model $2\left(R_{\text {conditional }}^{2}=.62 ; R_{\text {marginal }}^{2}=.08\right)$.

Importantly, Model 2 revealed a significant interaction between Social Relationship and Age predicting evaluation judgments, $F(2,502)=20.61, p<.001$. The other two-way interactions-Age x Scenario and Social Relationship x Scenario-were not significant ( $p s>$ .447). The observed interaction between Social Relationship and Age revealed a developmental shift in evaluation judgments (Figure 2). As was the case for our obligation analyses, we unpacked this interaction in two ways. First, we examined the effect of Social Relationship at older and younger ages on evaluations. Second, we examined the simple slopes of age on evaluations for each social relationship.

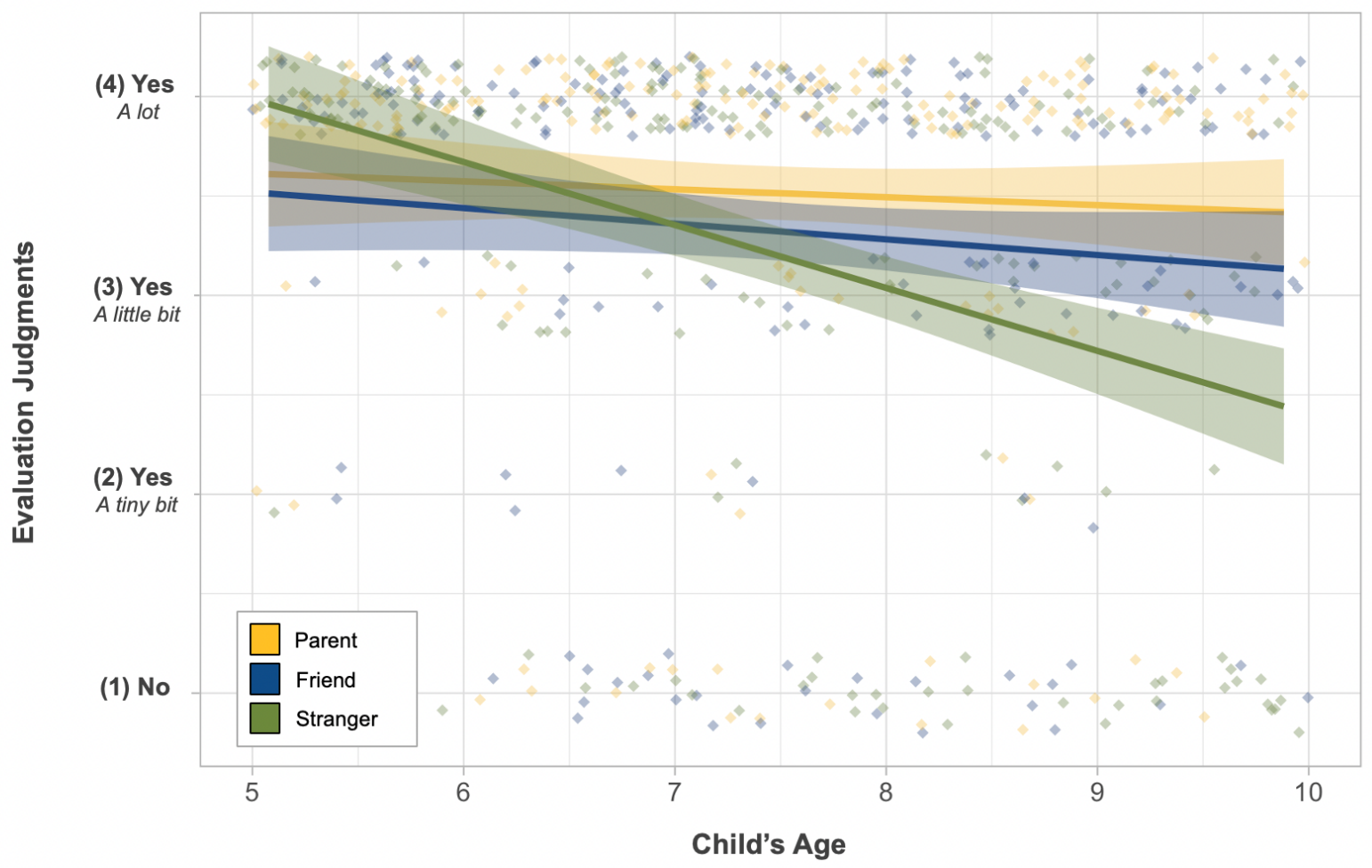

Figure 2 | Child participants' evaluation judgments as a function of Social Relationship (parent, friend, stranger) and Age (continuous). Error bars represents \pm one standard error.

The results of both analyses were largely similar to the observed obligation results. With respect to the former analysis, younger children (-1.5 SD; Age: 5.35) exhibited some discrimination in their evaluations of unhelpful others, $F(2,502)=4.78, p=.009$, but older children's evaluations were considerably more discriminate than younger children's, $F(2,502)=$ 23.16, $p<.001$ (see Table 2 for pairwise comparisons). The latter analyses revealed that-as illustrated in Figure 2 - age did not correlate with children's evaluations of unhelpful parents, $B=$ $-0.04, S E=0.07,95 \%$ CI [-0.17, 0.09]; $t=-0.61, p=.542$. Furthermore, and unlike for obligation judgments, age did not correlate negatively with meanness evaluations of unhelpful friends, $B=$ $0.08, S E=0.07,95 \%$ CI $[-0.21,-0.05] ; t=-1.21, p=.228$; we examine this potential difference in the next results section. Finally, and akin to obligation judgments, age did correlate negatively 
with children's evaluations of unhelpful strangers; that is, older children judged unhelpful strangers as less mean that younger children did, $B=-0.32, S E=0.07,95 \% \mathrm{CI}[-0.45,-0.19] ; t=$ $4.86, p<.001$. In summary, younger children were more inclined to judge parents, friends, and strangers similarly mean for failing to help in comparison to older children, who generally judged unhelpful parents the most harshly followed by friends and then strangers.

We also conducted the same subsidiary analyses for evaluations as were conducted for obligations (e.g., binary, expectation controls, adult-child comparisons); we have relegated these analyses to SOM for brevity's sake, but the analyses revealed the same robustness as was observed for obligations. Also, see Table 2 for pairwise comparisons that include adults.

Table 2. Means, standard errors, pairwise comparisons, effect sizes, and effect size confidence intervals for comparisons within younger and older children for evaluations of unhelpful others. $\diamond$ indicate the pairwise comparison in question.

\begin{tabular}{|c|c|c|c|c|}
\hline & Parent & Friend & Stranger & Significance Test \\
\hline \multirow{4}{*}{$\begin{array}{l}\text { Younger Children } \\
(-1.5 S D \text {; Age: } 5.35)\end{array}$} & $\begin{array}{l}3.60 \\
(.17)\end{array}$ & $\begin{array}{l}3.49 \\
(.17)\end{array}$ & $\begin{array}{l}3.87 \\
(.17)\end{array}$ & $F(2,502)=4.78, p=.009$ \\
\hline & $\diamond$ & $\diamond$ & & $B=0.11, S E=.12, t=.92, p=.629 ; 95 \%$ CI $[-0.17,0.39]$ \\
\hline & $\diamond$ & & $\diamond$ & $B=-0.28, S E=.12, t=2.33, p=.053 ; 95 \%$ CI $[-0.55,0.003]$ \\
\hline & & $\diamond$ & $\diamond$ & $B=-0.39, S E=.12, t=3.25, p=.004 ; 95 \%$ CI $[-0.66,-0.11]$ \\
\hline \multirow{4}{*}{$\begin{array}{c}\text { Older Children } \\
\text { (1.5 SD; Age: 9.59) }\end{array}$} & $\begin{array}{l}3.43 \\
(.17)\end{array}$ & $\begin{array}{l}3.16 \\
(.17)\end{array}$ & $\begin{array}{l}2.54 \\
(.17)\end{array}$ & $F(2,502)=23.15, p<.001$ \\
\hline & $\diamond$ & $\diamond$ & & $B=0.27, S E=.12, t=2.31, p=.056 ; 95 \% \mathrm{CI}[-0.005,0.55]$ \\
\hline & $\diamond$ & & $\diamond$ & $B=0.89, S E=.12, t=7.54, p<.001 ; 95 \%$ CI $[0.62,1.17]$ \\
\hline & & $\diamond$ & $\diamond$ & $B=0.62, S E=.16, t=5.23, p=.005 ; 95 \%$ CI $[0.34,0.90]$ \\
\hline \multirow{4}{*}{ Adults } & $\begin{array}{l}3.62 \\
(.18)\end{array}$ & $\begin{array}{l}3.04 \\
(.18)\end{array}$ & $\begin{array}{l}1.68 \\
(.18)\end{array}$ & $F(2,122)=84.62, p<.001$ \\
\hline & $\diamond$ & $\diamond$ & & $B=0.58, S E=.14, t=4.22, p<.001 ; 95 \%$ CI $[0.26,0.90]$ \\
\hline & $\diamond$ & & $\diamond$ & $B=1.94, S E=.14, t=14.10, p<.001 ; 95 \%$ CI $[1.62,2.26]$ \\
\hline & & $\diamond$ & $\diamond$ & $B=1.36, S E=.14, t=9.89, p<.001 ; 95 \%$ CI $[1.04,1.68]$ \\
\hline
\end{tabular}

\subsubsection{Comparing obligation and evaluation judgments}

Given that age negatively correlated with obligation judgments but did not correlate with evaluation judgments (meanness) in the friend condition, we considered the possibility that participants' obligations and evaluations diverge in exploratory analyses. To test this possibility, we built four different models. Model 1 included the main effects of Age (continuous), Social 
Relationship (parent, friend, stranger; within-participants), Scenario (fair, playground; withinparticipants), and Response Type (Obligation Judgments, Evaluation Judgments; withinparticipants). Model 2 added all two-way interactions between all four of these predictor variables. Model 3 further added all three-way interactions between all four predictor variables, and Model 4 added the single four-way interaction.

In doing so, we found Models 2-4 to exhibit improved model fit beyond Model $1\left(\chi^{2}\right.$ ranges between 75.20 and 84.44, all $p$ s $<.001$ ), while Models 2-4 did not exhibit improved model fit compared to each other $\left(0.21<\chi^{2}<9.03\right.$, all $p$ s $\left.>.250\right)$. Though we observed similar model fit amongst Models 2-4, we still observed a significant three-way interaction between Age, Social Relationship, and Response Type in Model 3, $F(2,1102)=4.11, p=.017$. In turn, we exploratorily examined this interaction. As illustrated when comparing Figures 1 and 2, we found differences in how age differentially impacted obligation judgments (relative to evaluations) for friends but not parents or strangers. While children's obligations judgments regarding friends decreased with age, children's evaluations of unhelpful friends as mean did not decrease with age (Table 3; Supplemental Figure 8). In summary, children with increasing age considered friends less obligated to help but did not consider such individuals less mean for not helping, pointing toward subtle differences in evaluations and obligations. These analyses, though, are exploratory and should be interpreted with caution.

Table 3. Effect sizes $(B), 95 \%$ confidence intervals (in brackets), and test statistics for relationships between age and judgments (obligation and evaluation) for each social relationship category (parent, friend, stranger).

\begin{tabular}{|c|c|c|c|c|c|c|}
\hline & \multicolumn{3}{|c|}{ Obligation Judgments } & \multicolumn{3}{|c|}{ Evaluation Judgments } \\
\hline & $B$ & $t$ & $p$ & $B$ & $t$ & $p$ \\
\hline Parent & $\begin{array}{c}-0.04 \\
{[-0.20,0.12]}\end{array}$ & -0.49 & .625 & $\begin{array}{c}-0.04 \\
{[-0.17,0.09]}\end{array}$ & -0.61 & .452 \\
\hline Friend & $\begin{array}{c}-0.31 \\
{[-0.46,-0.15]}\end{array}$ & -3.86 & $<.001$ & $\begin{array}{c}-0.08 \\
{[-0.21,0.05]}\end{array}$ & -1.21 & .228 \\
\hline Stranger & $\begin{array}{c}-0.29 \\
{[-0.45,-0.13]}\end{array}$ & -3.65 & $<.001$ & $\begin{array}{c}-0.32 \\
{[-0.45,-0.19]}\end{array}$ & -4.86 & $<.001$ \\
\hline
\end{tabular}

\subsection{Discussion}

Study 1 established a developmental shift in children's sense of prosocial obligation. Younger children reasoned more broadly about social-relational prosocial obligations. They considered individuals more obligated to help one another regardless of social relationship and judged unhelpful others as similarly mean compared to older children and adults, who reasoned more discriminately. Specifically, older children and adults considered parents most obligated to help followed by friends and then strangers and also evaluated unhelpful parents more harshly than unhelpful friends followed by unhelpful strangers (though subtle differences between obligation and evaluation judgments appeared in the case of unhelpful friends; see above). Importantly, the 
observed patterns were robust to various analyses, including examining responses in a binary format, controlling for variability in prosocial expectations, and including adults in the sample.

\section{Study 2}

In Study 2, we extended the findings of Study 1 across cultures. We examined whether children and adults growing up in cultural contexts aside from the United States (specifically, in Germany, India, Japan, and Uganda) also exhibit the observed developmental shift from broader to narrower prosocial obligations. To do so, we took a broad approach to test children in as many cultures as possible (the "breadth" approach; Amir \& McAuliffe, 2020), given the lab's monetary, recruitment, and practical constraints. Importantly, the samples we recruited varied on several cultural dimensions including Westernization, industrialization, and collectivism (Muthukrishna et al., 2020). Notably, if we find that younger children's prosocial obligation judgments are less sensitive to social relationship than older children's and adults' even in divergent cultural contexts, it would provide evidence that the human default may be to initially reason broadly about prosocial obligations rather than narrowly.

When choosing which cultures to include, we focused on finding highly divergent sites that varied on a number of cultural dimensions. For instance, Germany (Hamburg) and the United States (New Haven) represent Western testing sites, while India (Vadodara), Japan (Tokyo), and Uganda (Seeta Nazigo) do not. Additionally, Germany, India, Japan, and the United States represent more urban and industrialized environments, while Uganda is considerably more rural and not industrialized. Germany and the United States also represent individualistic cultures (Hofstede, 2011), whereas other included countries represent a mixture of individualism or collectivism (Japan; Takano \& Osaka, 2018; Ogihara, 2017) or are fairly collectivistic (India, Uganda; Kapoor, Hughes, Baldwin, \& Blue, 2003; Rarick, Winter, Nickerson, Falk, Barczyk, \& Asea, 2013). And, finally, testing in Germany, India, and the United States allowed us to compare our findings to previous cross-cultural research on prosocial obligations (Miller et al., 1990; Mammen et al., 2021).

\subsection{Method}

\subsubsection{Pre-registration information}

We pre-registered our main developmental analyses and data exclusions at: https://aspredicted.org/blind.php? $\mathrm{x}=6 \mathrm{k} 25 \mathrm{pw}$. See SOM for full information about the scope of the pre-registration.

\subsubsection{Child participants}

For Study 2, we aimed to collect 20 children per categorical age (between the ages of 5 and 10 years) within each culture. We ultimately recruited a total of 592 children: 123 5- to 10-yearolds from the United States, 129 5- to 10-year-olds from Germany, 103 6- to 10-year-olds from India, 110 6- to 10-year-olds from Japan, and 127 5- to 10-year-olds from Uganda (see SOM for 
detailed site descriptions). A sensitivity analyses revealed that, within each cultural sample, we had $95 \%$ power to find a small to medium Social Relationship x Age effect $(f=\sim .18$ or higher).

Table 4. Descriptive information for the cross-cultural samples in Study 2. Because we were not able to collect precise age in Uganda, we do not report the mean and standard deviation for age within that culture.

\begin{tabular}{|c|c|c|c|c|c|c|c|}
\hline $\begin{array}{c}\text { Country } \\
\mathrm{M}_{\text {age }}\left(\mathrm{SD}_{\text {age }}\right) \\
\% \text { female }\end{array}$ & 5 -yos & 6-yos & 7-yos & 8-yos & 9-yos & 10 -yos & Overall \\
\hline $\begin{array}{c}\text { Germany } \\
7.40(1.62) \\
52.7 \%\end{array}$ & 22 & 19 & 26 & 25 & 22 & 15 & 129 \\
\hline $\begin{array}{c}\text { India } \\
8.03(1.43) \\
33 \%\end{array}$ & 0 & 20 & 21 & 20 & 20 & 22 & 103 \\
\hline $\begin{array}{c}\text { Japan } \\
8.18(1.43) \\
51.8 \%\end{array}$ & 0 & 17 & 24 & 20 & 20 & 29 & 110 \\
\hline $\begin{array}{c}\text { Uganda } \\
\text { NA (NA) } \\
48 \%\end{array}$ & 20 & 20 & 25 & 21 & 22 & 19 & 127 \\
\hline $\begin{array}{c}\text { USA } \\
7.48(1.72) \\
47.7 \%\end{array}$ & 21 & 20 & 22 & 18 & 22 & 20 & 123 \\
\hline Overall & 63 & 96 & 118 & 104 & 106 & 105 & 592 \\
\hline
\end{tabular}

\subsubsection{Adult participants}

We collected a corresponding adult sample within each country. We aimed to collect as many participants as possible (up to 100 participants) in each country. We ultimately recruited a total of 446 adults: 93 from the United States, 90 from India, 100 from Japan, 77 from Germany, and 86 from Uganda (see SOM for additional information about participant recruitment). A sensitivity analyses revealed that, within each cultural sample, we had 95\% power to find a small to medium Social Relationship effect $(f=\sim .18$ or higher). Across all countries, some additional adult participants were collected but were excluded for failing the online comprehension check (explained below; $n=34$ ). 


\subsubsection{Materials and procedures}

Both child and adult participants were presented with two story-sets with three sub-stories within a set, amounting to six stories. The stories were similar to Study 1; again, we presented participants with playground and fair stories. Rather than presenting all potential helpers simultaneously (as in Study 1), however, we presented each potential helper - the parent, friend, or stranger - in separate randomized sub-stories to minimize the possibility that people's judgments about who has to help are influenced by who else is around (i.e., diffusion of responsibility; Figure 4). For example, for the playground story in the Parent condition, the participant was told: “This is Emma, and this is Emma's mom. One day, Emma was at a park, and she fell down and hurt herself, so she was very sad. Emma's mom sees that Emma is hurt."

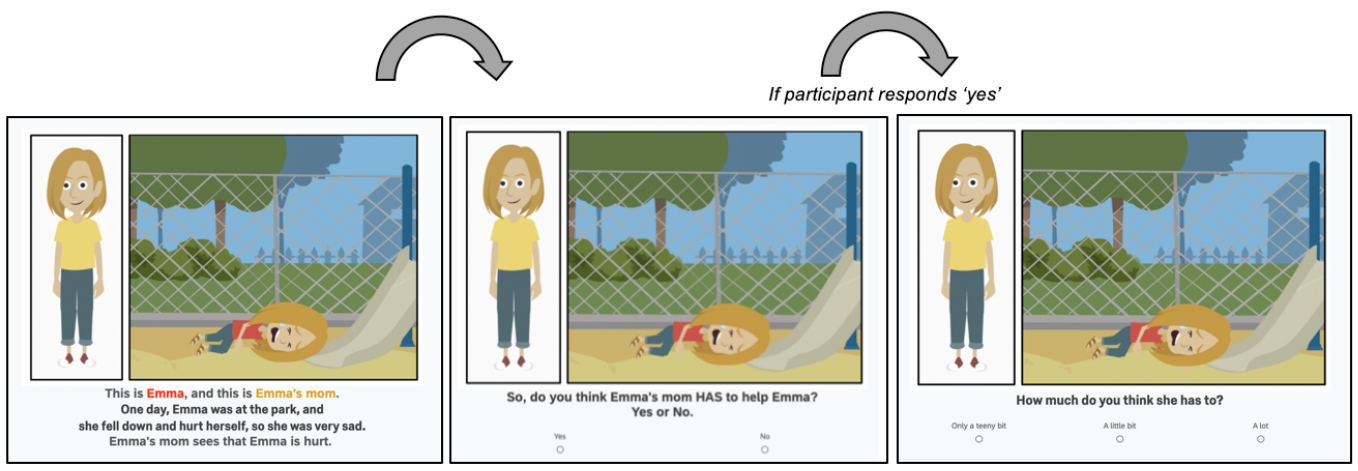

(A) Example playground story for Parent condition with obligation question
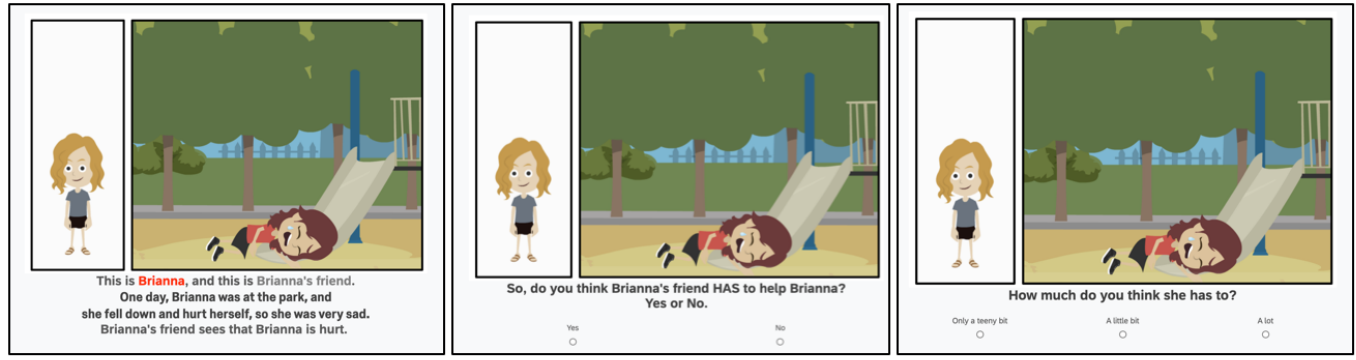

(B) Example playground story for Friend condition with obligation question
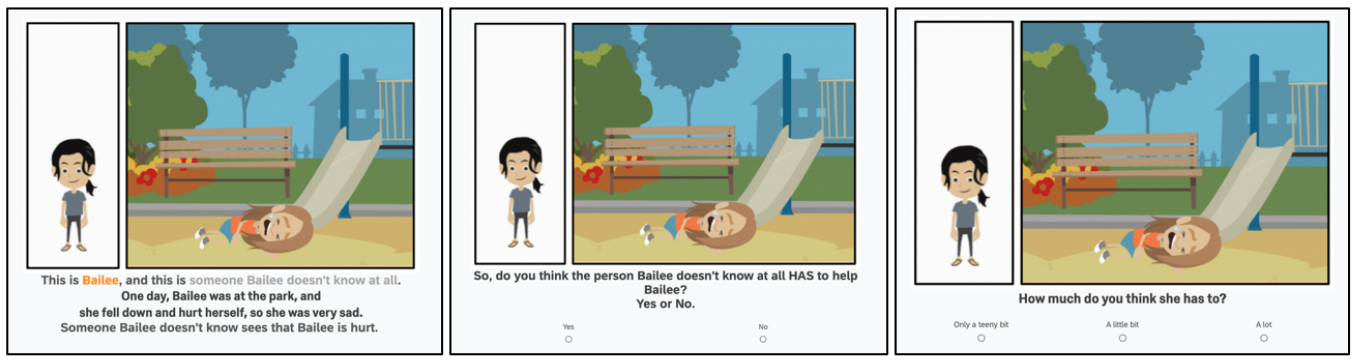

(C) Example playground story for Stranger condition with obligation question

Figure 4 | Examples of stimuli for the playground story in the United States. See links in SOM for verbatim materials. (C) 2019 GoAnimate, Inc. Images are copyrighted by and used by permission of VYOND ${ }^{\mathrm{TM}}$. VYOND is a trademark of GoAnimate, Inc., registered in Australia, Brazil, the European Union, Norway, the Philippines, Singapore, Switzerland and the United Kingdom. 
For each sub-story, we assessed obligation judgments. The wording of these questions was identical to Study 1. The experimenter asked, "Do you think Emma's mom has to help Emma? Yes or no?" If participants indicated "yes", we followed up by asking, "How much do you think she has to? A teeny bit, a little bit, or a lot?" We randomized which story-set participants heard first - the playground or the fair stories. Within each story-set, the order participants heard the substories (i.e., the parent, friend, or stranger) was randomized.

As in Study 1, we also assessed participants' expectation judgments about whether participants thought a bystander would help. As in Study 1, we included these questions to ensure that any results with respect to obligation judgments were not the result of systematic variability in children's expectations. As specified in the pre-registration, these questions were not the key focus of Study 2. We did not assess participants' evaluation judgments because we had found reasonably similar response patterns across obligation and evaluation judgments in Study 1 and needed to minimize the length of the study.

Finally, because we wanted to verify that participants understood the testing materials, we included two sets of comprehension check questions - one moral set and one preference setbased off of work by Miller and colleagues (1990). ${ }^{5}$ We included these questions to ensure participants understood the translated materials and also to ensure participants were not simply responding "yes" to any examples of obligations (i.e., any question including the phrase "have to"). For the moral comprehension questions, we asked two questions: (1) "This is Matt- he wants to buy this shirt. Does Matt have to steal this shirt?"; (2) "This is Marie-her mom asked her a question. Does Marie have to lie to her mom?" We counter-balanced the order of the questions. For the preference comprehension questions, we asked two questions: (1) "This is Andrew-he really likes these boots. He wants to buy these boots. Do you think Andrew has to buy these sneakers even though he wants to buy these boots?"; (2) "This is Sarah-her favorite color is yellow. She wants to wear a yellow shirt. Does she have to wear a blue shirt, even though she wants to wear a yellow one?" We counter-balanced the order of the questions.

All participants heard the study materials in their native language. All materials were translated by a native speaker and back-translated by a separate native speaker, and then reviewed for accuracy by yet another native speaker. The first author (and the third author, for Uganda) worked closely with translators to ensure the correct words were utilized for 'have to' compared to 'will' to ensure that the materials correctly translated the concept of obligation versus likelihood across all samples. The experimental procedures were also adapted to match the specific cultural context (i.e., characters' appearances, characters' names). The first author (and the third author, for Uganda) worked alongside the local research assistants to ensure that the materials reflected situations that are reasonably understandable to participants and represent situations that they may encounter in their everyday life. ${ }^{6}$ In all samples, the stories were presented on iPads and read to

\footnotetext{
${ }^{5}$ We did not include the comprehension check items for children in the United States in Study 2 because in Study 1, which was in the United States, children understood the questions.

${ }^{6}$ It is still possible, however, that some elements of the materials were differentially familiar to participants. Specifically, within the fair scenario, the potential helpers were presented with cotton candy and popcorn, which may be unfamiliar foods to children at some sites, such as India and Uganda. We discuss this further in the General Discussion.
} 
children by local research assistants in their native language (with the exception of India where the materials were presented in both Hindi and English).

\subsection{Method}

\subsubsection{Main analyses}

As in Study 1, we used the lme4 package in R to examine children's obligation judgments. We created four linear mixed-effects models with participant ID included as a random intercept to account for individual variability across participants. Model 1 included the main effects of Age (continuous; centered around zero), Social Relationship (parent, friend, stranger; withinparticipants), Scenario (fair, playground; within-participants), and Culture (Germany, India, Japan, Uganda, United States). Model 2 added all the two-way interactions; Model 3 added all the threeway interactions; and, Model 4 added the single four-way interaction amongst these variables. Model comparisons were calculated via likelihood ratio tests.

We found that Model 2 exhibited improved model fit compared to Model 1, $\chi^{2}=375.25, p$ $<001$. Model 3 further improved model fit beyond Model 2, $\chi^{2}=71.13, p<.001$. Model 4, though, did not improve model fit beyond Model 3, $\chi^{2}=5.60, p=.692$. As such, the following analyses were conducted with Model $3\left(R^{2}\right.$ conditional $=.57 ; R^{2}$ marginal $\left.=.27\right)$. Most relevant to the research question at hand, we found a three-way interaction between Social Relationship, Age, and Culture, $F(8,2906)=5.29, p<.001$ (Figure 5). To unpack this interaction, we examined the interaction between Age and Culture within each social relationship. In doing so, we found an Age x Culture interaction for all three types of social relationships, Parent: $F(4,577)=4.14, p=.003$, Friend: $F(4,581)=8.15, p<.001$, Stranger: $F(4,583)=10.84, p<.001$. 


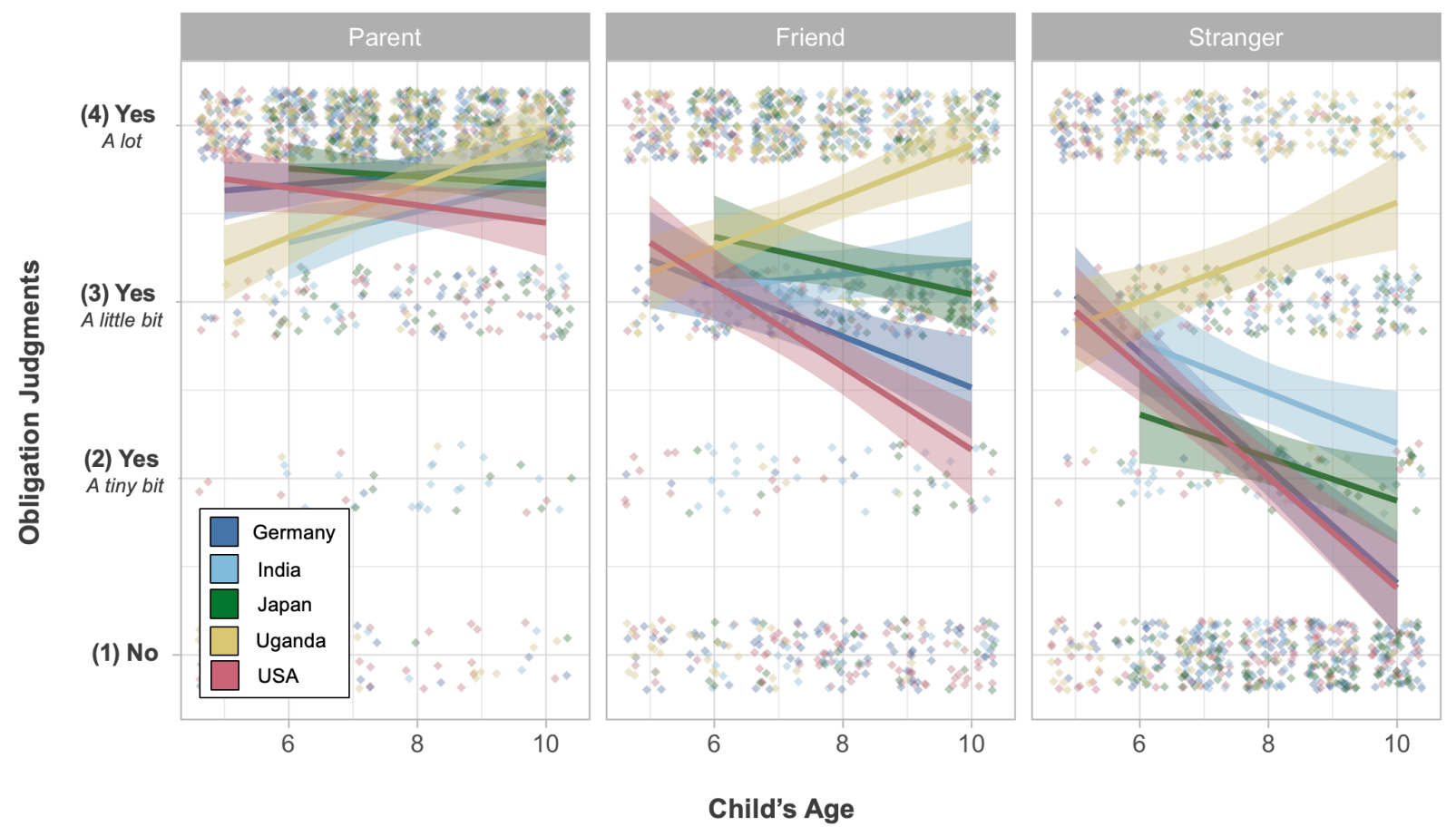

Figure 5 | Children's obligation judgments as a function of Social Relationship (parent, friend, stranger), Culture (Germany, India, Japan, Uganda, USA), and Age (continuous). See also Supplemental Figure 9 for alternative illustration of the Social Relationship x Age x Culture interaction. Error bars represents \pm one $S E$.

Next, we considered the simple effects of each of these two-way interactions. Even though we found a two-way interaction between Culture and Age for the Parent condition, the pairwise comparisons within these effects were non-significant, as illustrated by Figure 5. The only difference which survived the applied Bonferroni correction was that younger $(\beta=-0.42, S E=$ $0.15, t=-2.87, p=.043)$ and older children in the United States $(\beta=.53, S E=0.17, t=3.21, p=$ .014) judged parents as less obligated to help than older children in Uganda (see Supplemental Table S1 for all other comparisons). This effect was largely driven by a ceiling effect-almost all older children in Uganda reported that a parent had to help their child to the highest degree.

We next considered the friend and stranger obligation judgments. Notably, younger children's obligation judgments for both the Friend and Stranger conditions did not vary depending on culture whatsoever (all $p \mathrm{~s}>$.753; Supplemental Tables S2 and S3). At older ages though, children's judgments about whether friends and strangers are obligated to help varied considerably depending on culture (Tables 4 and 5). With respect to friends, older children in Uganda rated friends most obligated to help followed by India, Japan, and Germany (the three of which did not significantly differ from one another) followed by the United States (which differed from India and Japan but not Germany). With respect to stranger judgments, older children in Uganda rated strangers most obligated to help followed by India, Japan, and Germany (the three of which did not significantly differ from one another) followed by the United States (which differed from India 
but neither Germany nor Japan). In sum, we find evidence that younger children across cultures reason more indiscriminately about prosocial obligations than older children, and further, that culture plays a key role in shaping whether children ultimately abandon the notion that we are obligated to help all individuals as they grow older.

Table 5. Friend Obligations: Means, standard errors (in parentheses), effect sizes, and 95\% confidence intervals for comparisons between Culture within only older children for friend obligation judgments. $\checkmark$ indicate the pairwise comparison in question. See Supplemental Table 2 for corresponding values for younger children and Supplemental Table 5 for corresponding values for adults.

\begin{tabular}{|c|c|c|c|c|c|}
\hline Germany & India & Japan & Uganda & USA & Significance Test \\
\hline $\begin{array}{l}2.50 \\
(.17)\end{array}$ & $\begin{array}{l}3.21 \\
(.17)\end{array}$ & $\begin{array}{l}3.03 \\
(.15)\end{array}$ & $\begin{array}{l}3.90 \\
(.16)\end{array}$ & $\begin{array}{l}2.14 \\
(.16)\end{array}$ & \\
\hline$\diamond$ & $\diamond$ & & & & $B=-0.71, S E=0.23, t=-3.04, p=.025 ; 95 \%$ CI $[-1.37,-0.05]$ \\
\hline$\diamond$ & & $\diamond$ & & & $B=-0.53, S E=0.23, t=-2.38, p=.175 ; 95 \%$ CI $[-1.17,0.10]$ \\
\hline$\diamond$ & & & $\diamond$ & & $B=-1.40, S E=0.23, t=-6.15, p<.001 ; 95 \%$ CI $[-2.05,-0.76]$ \\
\hline \multirow[t]{7}{*}{$\diamond$} & & & & $\diamond$ & $B=0.36, S E=0.23, t=1.59, p=1.00 ; 95 \%$ CI $[-0.28,1.00]$ \\
\hline & $\diamond$ & $\diamond$ & & & $B=0.18, S E=0.23, t=0.78, p=1.00 ; 95 \%$ CI $[-0.46,0.81]$ \\
\hline & $\diamond$ & & $\diamond$ & & $B=-0.69, S E=0.23, t=-3.01, p=.027 ; 95 \%$ CI $[-1.34,-0.04]$ \\
\hline & $\diamond$ & & & $\diamond$ & $B=1.07, S E=0.23, t=4.68, p<001 ; 95 \%$ CI $[0.43,1.72]$ \\
\hline & & $\diamond$ & $\diamond$ & & $B=-0.87, S E=0.22, t=-3.95, p<.001 ; 95 \%$ CI $[-1.49,0.25]$ \\
\hline & & $\diamond$ & & $\diamond$ & $B=0.90, S E=0.22, t=4.09, p<.001 ; 95 \%$ CI $[0.28,1.51]$ \\
\hline & & & $\diamond$ & $\diamond$ & $B=1.77, S E=0.22, t=7.91, p<.001 ; 95 \%$ CI $[1.14,2.39]$ \\
\hline
\end{tabular}


Table 6. Stranger Obligations: Means, standard errors (in parentheses), effect sizes, and $95 \%$ confidence intervals for comparisons between Culture within only older children for stranger obligation judgments. $\diamond$ indicate the pairwise comparison in question. See Supplemental Table 3 for corresponding values for younger children.

\begin{tabular}{|c|c|c|c|c|c|}
\hline Germany & India & Japan & Uganda & USA & Significance Test \\
\hline $\begin{array}{l}1.37 \\
(.18)\end{array}$ & $\begin{array}{l}2.20 \\
(.19)\end{array}$ & $\begin{array}{l}1.86 \\
(.17)\end{array}$ & $\begin{array}{l}3.58 \\
(.18)\end{array}$ & $\begin{array}{l}1.35 \\
(.18)\end{array}$ & \\
\hline$\diamond$ & $\diamond$ & & & & $B=-0.83, S E=0.26, t=-3.14, p=.018 ; 95 \%$ CI $[-1.57,-0.09]$ \\
\hline$\diamond$ & & $\diamond$ & & & $B=-0.49, S E=0.25, t=-1.94, p=.527 ; 95 \%$ CI $[-1.20,0.22]$ \\
\hline$\diamond$ & & & $\diamond$ & & $B=-2.21, S E=0.26, t=-8.63, p<.001 ; 95 \% \mathrm{CI}[-2.93,-1.49]$ \\
\hline \multirow[t]{7}{*}{$\diamond$} & & & & $\diamond$ & $B=0.03, S E=0.26, t=0.10, p=1.00 ; 95 \%$ CI $[-0.69,0.74]$ \\
\hline & $\diamond$ & $\diamond$ & & & $B=0.34, S E=0.25, t=1.33, p=1.00 ; 95 \% \mathrm{CI}[-0.38,1.05]$ \\
\hline & $\diamond$ & & $\diamond$ & & $B=-1.38, S E=0.26, t=-5.36, p<.001 ; 95 \%$ CI $[-2.11,-0.65]$ \\
\hline & $\diamond$ & & & $\diamond$ & $B=0.85, S E=0.26, t=3.31, p=.010 ; 95 \%$ CI $[0.13,1.58]$ \\
\hline & & $\diamond$ & $\diamond$ & & $B=-1.72, S E=0.25, t=-6.98, p<.001 ; 95 \%$ CI $[-2.41,-1.02]$ \\
\hline & & $\diamond$ & & $\diamond$ & $B=0.51, S E=0.25, t=2.10, p=.365 ; 95 \%$ CI $[-0.18,1.21]$ \\
\hline & & & $\diamond$ & $\diamond$ & $B=2.23, S E=0.25, t=8.94, p<.001 ; 95 \%$ CI $[1.53,2.94]$ \\
\hline
\end{tabular}

To further examine the simple effects, and as in Study 1, we conducted trend analyses to examine the simple slopes of age predicting obligation judgments for each culture and social relationship. These analyses revealed, in large part, that age does not relate to judgments about parental obligations in most cultures. The only exception was Uganda where, with age, children increasingly judged parents as obligated to help. With respect to friend and stranger obligations, however, we observed the largest shifts in age in Germany and the United States, where children judged friends and strangers as less obligated to help increasingly so with age. In Uganda, however, the opposite pattern emerged (see Table 7). 
Table 7. Trend analyses of relationships between Social Relationship and Age for each Social Relationship across each Culture.

\begin{tabular}{|c|c|c|c|c|c|c|c|c|c|}
\hline & \multicolumn{3}{|c|}{ Parent } & \multicolumn{3}{|c|}{ Friend } & \multicolumn{3}{|c|}{ Stranger } \\
\hline & $B$ & $t$ & $p$ & $B$ & $t$ & $p$ & $B$ & $t$ & $p$ \\
\hline Germany & $\begin{array}{c}0.03 \\
{[-0.04,0.11]}\end{array}$ & 0.81 & .417 & $\begin{array}{c}-0.14 \\
{[-0.25,-0.04]}\end{array}$ & -2.78 & .006 & $\begin{array}{c}-0.33 \\
{[-0.44,-0.21]}\end{array}$ & -5.58 & $<.001$ \\
\hline India & $\begin{array}{c}0.09 \\
{[-0.01,0.18]}\end{array}$ & 1.74 & .083 & $\begin{array}{c}-0.03 \\
{[-0.10,0.16]}\end{array}$ & 0.41 & .679 & $\begin{array}{c}-0.14 \\
{[-0.28,-0.01]}\end{array}$ & -1.86 & .064 \\
\hline Japan & $\begin{array}{c}-0.02 \\
{[-0.12,0.07]}\end{array}$ & -0.50 & .621 & $\begin{array}{c}-0.08 \\
{[-0.21,-0.04]}\end{array}$ & -1.28 & .200 & $\begin{array}{c}-0.12 \\
{[-0.26,0.02]}\end{array}$ & -1.71 & .087 \\
\hline Uganda & $\begin{array}{c}0.15 \\
{[0.07,0.22]}\end{array}$ & 3.90 & $<.001$ & $\begin{array}{c}0.14 \\
{[0.04,0.24]}\end{array}$ & 2.83 & .005 & $\begin{array}{c}0.14 \\
{[0.03,0.25]}\end{array}$ & 2.44 & .015 \\
\hline USA & $\begin{array}{c}-0.05 \\
{[-0.12,0.02]}\end{array}$ & -1.33 & .184 & $\begin{array}{c}-0.23 \\
{[-0.33,-0.14]}\end{array}$ & -4.67 & $<.001$ & $\begin{array}{c}-0.31 \\
{[-0.42,-0.20]}\end{array}$ & -5.57 & $<.001$ \\
\hline
\end{tabular}

\subsubsection{Secondary analyses}

Similar to Study 1, we conducted four secondary analyses. First, we examined whether the same pattern of results emerge even if we consider participants' responses in a binary manner. When doing so, we found only two responses in Japan where participants judged a parent as not obligated to help, which lead to convergence issues in the models. To resolve this, we excluded Japan in our main analyses examining binary obligation responses. As above, we found that Model 2 exhibited improved model fit compared to Model $1, \chi^{2}=153.74, p<001$. Model 3 further improved model fit beyond Model $2, \chi^{2}=41.69, p=.001$. Finally, Model 4 did not improve model fit beyond Model 3, $\chi^{2}=2.86, p=.826$. Importantly, replicating the non-binary analyses, we again observed the Social Relationship x Age x Culture interaction in Model 3, $\chi^{2}=15.97, p=.014$ (Supplemental Figure 10). For model outputs and simple effects related to this analysis and all other secondary analyses, see RMarkdown file on OSF.

Second, we considered the possibility that children's variation in obligation judgments may emerge because of variation in expectation judgments. To address this possibility, we first examined whether the Social Relationship x Age x Culture interaction found for obligation judgments also emerges for expectation judgments. To do so, we reconducted the four main models but with expectations as the outcome variable instead of obligations. Similar to obligations in Studies 1 and 2 (but unlike expectations in Study 1), we found that Model 2 did exhibit enhanced model fit over Model $1\left(\chi^{2}=367.43, p<.001\right)$, as did Model 3 over Model $2\left(\chi^{2}=51.32, p<.001\right)$; Model 4 did not exhibit enhanced model fit over Model $3\left(\chi^{2}=11.04, p=.200\right)$. Specifically, when examining Model 3, we found a Social Relationship, Age, and Culture interaction predicting expectations, $F(8,2913)=3.13, p=.002$ (Supplemental Figure 11). Unlike in Study 1 where expectation judgments patterned differently than obligation judgments - expectation judgments 
and obligation judgments tended to exhibit similar patterns in this study (see Supplemental Figure 12). ${ }^{7}$ To account for this overlap between obligation and expectation judgments, we tested whether the observed Social Relationship x Age x Culture interaction predicting obligations remained when including expectation judgments as a control (main effect of expectations and all possible twoway and three-way interactions) in the model. Notably, we found that the interaction between Social Relationship, Age, and Culture predicting obligations remained when doing so, $F(8,2953)$ $=2.98, p=.002 .^{8}$ As such, expectation judgments cannot account for the observed obligation findings.

Third, we excluded any participants who responded 'no' to the immoral behavior questions ${ }^{9}$ to ensure the observed obligation findings were not the result of younger children potentially lacking an understanding of the materials or an unwillingness to respond 'no' to an experimenter. In total, 69 children were excluded $\left(n_{\text {Germany }}=14 ; n_{\text {India }}=21 ; n_{\text {Japan }}=15 ; n_{\text {Uganda }}=\right.$ 19; Supplemental Table 7; Supplemental Figure 13); no children from the USA were excluded because the immoral questions were not asked in that particular sample (see Footnote 5). In doing so, we still found that Model 2 exhibited improved model fit over Model 1, $\chi^{2}=343.51, p<.001$, and Model 3 exhibited improved model fit of Model 2, $\chi^{2}=73.56, p<.001$; Model 4 did not exhibit model fit over Model 3, $\chi^{2}=5.77 p=.673$. Demonstrating robustness, we again found the observed Social Relationship x Age x Culture interaction predicting obligation judgments, $F(8$, 2564) $=5.61, p=.015$.

Finally, we also compared children's responses to adults' responses. To do so, we ran the same four main models but, as in Study 1, changed age to a categorical variable (Age Group) with three levels: younger children, older children, and adults (younger and older children were categorized via a median split). In doing so, we again found that Model 2 exhibited improved fit over Model 1, $\chi^{2}=570.36, p<.001$, and Model 3 exhibited improved fit over Model 2, $\chi^{2}=163.63$, $p<.001$; Model 4 did not exhibit enhanced model fit over Model 3, $\chi^{2}=15.80, p=.467$. In line with our previously observed findings, we found an Age Group x Social Relationship x Culture interaction in Model 3, $F(16,5111)=3.34, p<.001$. Unpacking this interaction revealed that adults' obligation judgments largely echoed those of older children (Figure 6; Supplemental Figures 14-15).

Notably, these adult samples were not recruited within the same communities as the developmental sample and instead were recruited via online survey platforms (see SOM). Despite this, the same cultural findings documented with respect to older children persisted into adulthood.

\footnotetext{
${ }^{7}$ One possible explanation for this discrepancy relates to method differences between Study 1 and 2. In Study 1, the potential helpers were presented collectively, whereas potential helpers were presented individually in Study 2. Perhaps younger children do not expect strangers to help when they are in the presence of other potential helpers (such as parents or friends) but do expect strangers to help in the absence of other potential helpers. Future research is required to test this, however.

${ }^{8}$ This key interaction between Social Relationship x Age x Culture also remains if we include the four-way interaction between Social Relationship x Age x Culture x Expectations in the model, $p=.006$.

${ }^{9}$ We also included a set of items about whether participants' think others have to act against their preferences (see 'Methodology'). Because participants were more willing to respond 'yes' to this question compared to the immoral questions, excluding participants who responded 'yes' to the preference questions would considerably reduce the sample. Even still, we conducted such analyses to provide the most conservative test of whether our effects emerge because children are unwilling to respond 'no'. Importantly, we still found the observed Social Relationship x Age x Culture interaction in Model 3 when doing so, $F(8,1899)=4.25, p<.001$.
} 
That is, adults generally considered parents obligated to help regardless of culture, but cultural variation similar to older children's responses emerged with respect to both friends and strangers (Figure 6; Supplemental Tables 4-6). These results suggest that cultural differences in adults' responding are an actual reflection of cultural variation and not just site-specific differences across cultures.

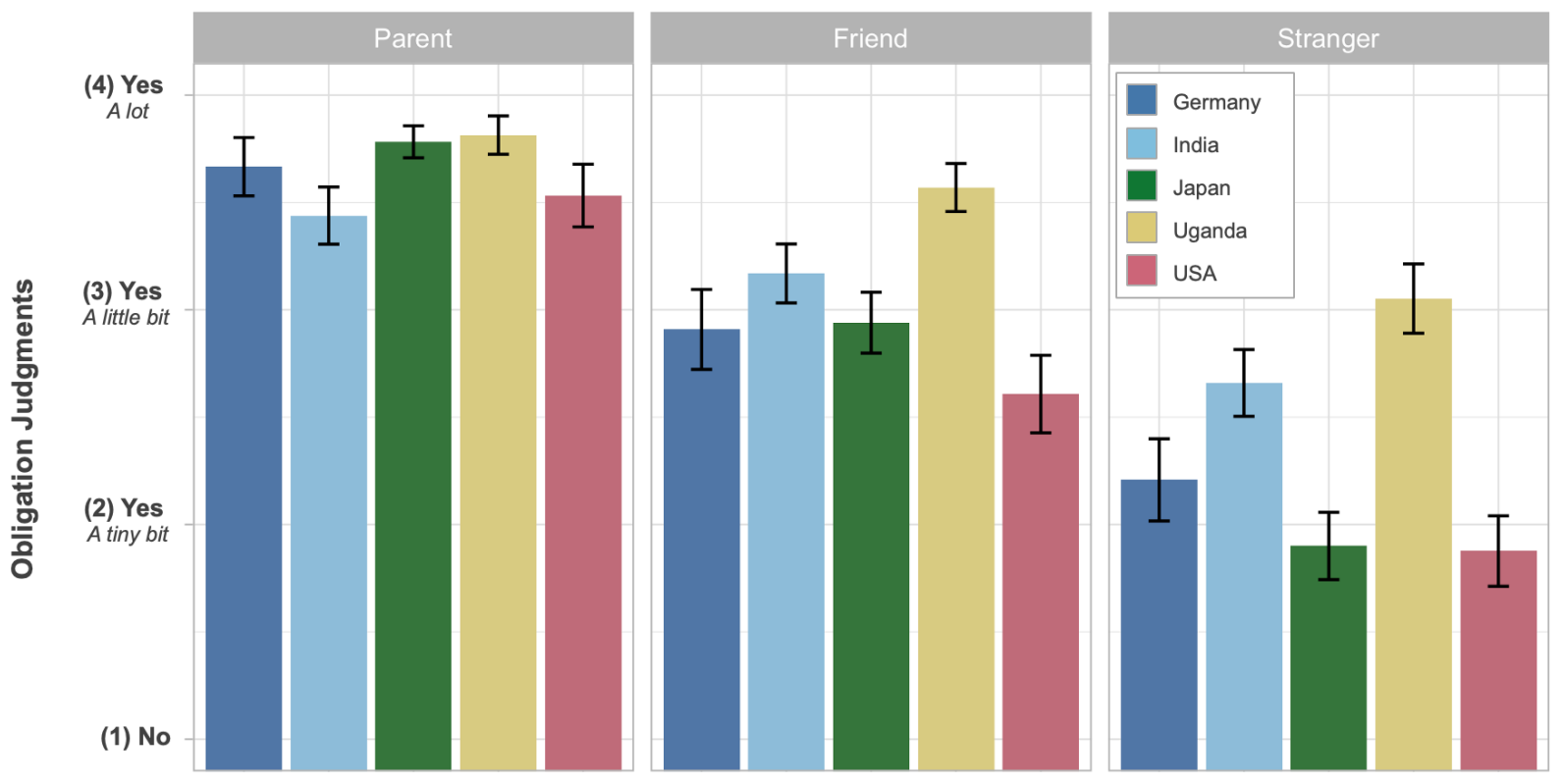

Figure 6 | Adults' obligation judgments as a function of Social Relationship (parent, friend, stranger) and Culture (Germany, India, Japan, Uganda, USA). Error bars represents plus/minus one $S E$.

\subsection{Discussion}

Building on Study 1, Study 2 investigated whether younger children across disparate cultures reason indiscriminately about prosocial obligations and how culture may impact prosocial obligation judgments at older ages and into adulthood. For the most part, children across all cultures regardless of age considered parents obligated to help their children. Importantly, though, when it comes to friends and strangers, we found considerable developmental and cultural variability. For example, younger children in the United States and Germany tended to judge friends and strangers as more obligated to help than older children did, although the same was not the case of older children either in Japan, India, or Uganda. In Uganda, the reverse age effect emerged such that older children were more inclined than younger children to consider friends and strangers obligated to help one another. In Japan and India, no age effects emerged - in those samples, age tended to negatively correlate with considering friends and strangers obligated to help one another, although these relationships did not reach significance. Importantly, the observed patterns were robust to various analyses, including examining responses in a binary format, controlling for variability in prosocial expectations, and including adults in the sample. These findings in addition to the findings of Study 1 then suggest that the default way of reasoning about prosocial obligations in relational contexts may be indiscriminate. 


\section{General Discussion}

In two studies, we observed a broad-to-narrow developmental shift in children's reasoning about prosocial obligations. Younger children tended to judge everyone as obligated to help someone-in-need (including strangers; Studies 1 and 2), even across widely varying cross-cultural contexts (Germany, India, Japan, Uganda, United States). Additionally, we found a similar pattern for evaluations of unhelpful others: younger children across cultures rated unhelpful parents, friends, and strangers as similarly mean for failing to help (Study 1). In contrast, older children and adults typically exhibited more narrow prosocial obligations. They judged parents as obligated to help followed by friends and then strangers (Studies 1 and 2) and rated unhelpful parents as meanest followed by unhelpful friends and then unhelpful strangers (Study 1). The shift from broad obligations to narrower ones was stronger in some cultural contexts (i.e., USA, Germany) than others (i.e., India, Japan), however, and the shift was non-existent in Uganda, where children and even adults reasoned broadly about obligations. Importantly, these findings were robust to various analytical choices, including transforming participants' responses to binary format, controlling for participants' expectation judgments (likelihood judgments of whether someone will help), and treating age as continuous versus categorical (younger vs. older children).

\subsection{Theoretical contributions}

Our findings contribute to our understanding of how social relationships impact social judgment. Specifically, scholars have recently emphasized how psychology as a field has largely focused on interactions between strangers, even though the majority of our day-to-day interactions tend to be with close others, such as friends and family members (Bloom, 2011; Hester \& Gray, 2020; Schein, 2020). Further, scholars have also argued that, as a field, we have only a very cursory understanding of how humans conceptualize obligation (Tomasello, 2020). In the hopes of filling some of these gaps, the present research paints a picture of how social relationships impact our sense of who is obligated to help one another. More specifically, the present results challenge an assumption in many philosophical arguments about the nature of human morality - the idea that morality starts off narrow and expands through development (e.g., Singer, 1981). Instead, our results suggest that children's initial sense of prosocial obligation starts out broad and the effect of cultural exposure and development is generally to make children more (rather than less) selective.

Additionally, the present findings cohere with and extend previous research, including work on how adults in the United States reason about social-relational obligations. Specifically, we replicate previous studies showing that adults in the United States take social relationship into account when evaluating unhelpful others and also when determining obligations (Earp et al., 2021; Haidt \& Baron, 1996; McManus et al., 2020). And, with respect to adults outside of the United States, we replicate previous studies documenting variation in adults' sense of prosocial obligation between the United States and India (Miller et al., 1990). Finally, we extend this past work by observing cultural variation in prosocial obligation judgments in other countries as well, including Japan, Uganda, and Germany.

The present research also replicates and extends past developmental work. For instance, we replicate findings that children between the ages of three and five consider individuals equally obligated to help regardless of social relationship (Dahl et al., 2020) and that children around the 
age of seven begin to consider social relationship when ascribing prosocial obligations (Marshall et al., 2020; Marshall, Mermin-Bunnell, \& Bloom, 2020; Miller et al., 1990). Additionally, our findings replicate past cross-cultural developmental effects. Specifically, as in Miller and colleagues (1990), we found that children in India reason comparatively more broadly than children in the United States in terms of prosocial obligations. Finally, extending this past work, we found that children across numerous cultures start with broad prosocial obligation judgments (across Germany, India, Japan, Uganda, United States), and that cultural variation emerges among these judgments during the middle childhood period.

Beyond prosocial obligation judgments, previous research has considered prosocial behavior. Many studies have sought to examine how discriminant children's actual helping behavior is relative to adults' (e.g., Dunfield \& Kuhlmeier, 2010). This research, at least from our perspective, has rendered mixed results (see different perspectives, see Bloom, 2013; Callaghan \& Corbit, 2018; Warneken \& Tomasello, 2009; Wynn et al., 2018), ultimately making it challenging to draw any firm parallels between the present work and past research on prosocial behavior. For example, some behavioral work has found children to behave in partial ways in early childhood. For instance, Olson and Spelke (2008) found that children around the age of three distribute more resources to a sibling and friend compared to a stranger (see also, Engelmann et al., 2019, 2021; Lenz \& Paulus, 2021; Moore, 2009). However, other research has found that younger children are more indiscriminate in their giving behavior compared to older children (Barragan, Brooks, \& Meltzoff, 2020; Güroğlu, van de Bos, \& Cone, 2014; Li, Wy, Hou, Zeng, Jiang, \& Zhang, 2021; Lu \& Chang, 2016; Paulus \& Moore, 2014; Rao \& Stewart, 1999; Scharpf, Paulus, \& Worle, 2017; Vonk, Jett, Tomeny, Mercer, \& Cwilka, 2020; Yu, Zhu, \& Leslie, 2016). For instance, recent work by Barragan-Jason and colleagues (2021) found that children are more successful cooperators with non-kin compared to kin.

Given that at least some work finds that young children exhibit discriminate behavior (e.g., Engelmann et al., 2021), it points towards the possibility that children's helping behavior toward others may be conceptually distinct from their intuitions about whether people are obligated to help others. We see similar dissociations elsewhere. For instance, developmental research has found that children at young ages express an understanding of what is fair-they think others should distribute resources equally - while they themselves do not engage in equal distribution (Blake, McAuliffe, \& Warneken, 2014). It is then not necessarily paradoxical to find that children express the belief that everyone is equally obligated to help, even if they themselves may be biased in their own helping behaviors.

\subsection{Key questions}

Why do younger children across cultures espouse broader notions of prosocial obligation? It is unlikely that the observed developmental shift emerged because young children are confused about social relationships. Other research has found that children around the age of five exhibit a mature understanding of such relationships (e.g., Benson \& Anglin, 1987; Spokes \& Spelke, 2016). And, we do not think our findings are driven by younger children responding in a more socially desirable way than older children. Research indicates that, if anything, older children (rather than younger children) are more susceptible to social desirability bias (Dunham, Baron, \& Banaji, 2008; Raabe \& Beelmann, 2011). 
Instead, we view the current results as reflecting a relative indifference towards social relationships in young children's reasoning about prosocial obligations, one that might arise for good reason. After all, young children tend to be generally surrounded by trusted others, whether it be their family or local community members. It is not until later in life that children start to interact more regularly with those who may be indifferent to their fates (or even malevolent). As such, assuming that everyone is obligated to help one another might be a plausible natural default. Only later, potentially through cultural exposure to norms (House et al., 2013, 2020), may children come to adopt different notions of obligation based on their surrounding environment.

Beyond younger children, why do older children and adults, depending on cultural context, espouse narrower notions of prosocial obligation? In what follows, we first consider several explanations that we ultimately find unlikely, and then turn to what we see as a more plausible account. First, it is possible that variation has very little to do with cultural variation at the countrylevel and instead can be attributed to differences in the specific sites where we tested children (e.g., Green, Deschamps, \& Paex, 2005; Yamawaki, 2012). Providing evidence against this possibility, however, we found similar variation in adults' and older children's prosocial obligations, even though adult participants were mostly recruited via online survey platforms from different locations within the same country as the child participants (see SOM). This then suggests that variation in older children's and adults' prosocial obligation judgments is attributable to specific country-level cultural differences where we tested participants (rather than to the site-specific differences or method, for instance, online or in-person data collection).

Second, it is possible that societal variation emerged because of linguistic differences (Bender, 2020). Perhaps the translations of 'have to' signaled different meanings in different countries, resulting in societal variability. However, we worked carefully with local translators to ensure that 'have to' was appropriately conveyed across the different testing sites. Additionally, it is unclear why linguistic variation would specifically impact older children's judgments and not younger's or why controlling for responses on the 'immoral obligation questions' would not account for such variation.

Third, perhaps children in some samples (e.g., Uganda, India) are especially unfamiliar with certain components of the stimuli. For example, the fair scenario may have been more unfamiliar to children in India, Japan, and Uganda because it portrayed children with popcorn and cotton candy. While this is a possibility, we find familiarity an unlikely explanation for societal differences. For one, we found similar developmental findings regardless of scenario. For another, the fair scenario would likely have been similarly unfamiliar to children in India and perhaps Japan as they were to children in Uganda, and yet, we found contrasting results between these countries.

Fourth, it is possible that societal variation emerged because of differences in the degree to which the samples were urban versus rural. Indeed, such variables impact social decision-making (e.g. Henrich et al., 2010). Although the present data cannot definitively speak on this issue, some of our results bear on this hypothesis. Specifically, in some of the adult samples (Germany, India, Uganda, United States), we asked participants to report whether they currently live in an urban (versus rural) environment, whether they grew up in an urban (versus rural) environment, and the comparative degree to which they have spent time in urban (versus rural) environments over the course of their life. These analyses revealed that cultural differences documented within adults 
was not attributable to variation in urban (versus rural) upbringing or lifestyle (see SOM), although future research could investigate this possibility more thoroughly.

Other than urban versus rural, our cross-cultural samples varied on a variety of dimensions, including (but not limited to) Westernization, collectivism versus individualism, and SES. Again, because of our samples do not vary systematically on any of these dimensions, we cannot directly examine the role of certain cultural factors in the development of prosocial obligation judgments. But we do suspect that variation in societal values related to collectivism and individualism may shape children's emerging sense of prosocial obligation. This proposal is motivated by the finding that participants in more collectivistic societies (Japan, India, Uganda) exhibited broader senses of obligation than those in more individualistic societies (Germany, United States) (see Hofstede, 2011; Rarick et al., 2013).

How would collectivism and individualism shape the development of our sense of obligation? After all, collectivism in a theoretical sense tends to emphasize obligations to the group - not necessarily to strangers (e.g., Brewer \& Chen, 2007). It is possible, however, that participants across societies view strangers in our stimuli as part of the cultural ingroup. After all, the characters in the stimuli are all the same ethnicity and also presumably live in the same community. The variance in responses we find, then, might be variance in the degree to which they consider individuals obligated to help ingroup strangers - and this in turn, may depend on cultural values, such as collectivism. Future research is best suited to address this question by examining how group membership and social relationship independently impact the development of obligation judgments across societies.

Regardless of which societal values ultimately impact children's sense of obligation, the findings raise the question of how this process occurs during childhood. Adults and trusted others may explicitly or implicitly teach children about societal values either via testimony or observation (e.g., Maccoby, 2007; Pratty \& Hardy, 2014; see Dahl, 2019 for a useful review). Through this process, children may then absorb this information, which ultimately alters children's obligation judgments. Alternatively, and in line with more of a Piagetian constructivist view (Piaget, 1932), children may update their beliefs about obligation through exploring how individuals in their community act toward one another and eliciting information about obligation from others (Dahl et al., 2018; Turiel, 2015, 1983). We hope future research will investigate these questions in greater detail.

Finally, the present findings also raise the question of whether similar developmental effects emerge in contexts outside of social relationships? We tested this possibility in a Supplemental Study, in which we investigated one boundary condition on young children's broader reasoning: knowledge (see SOM for full information). Specifically, we presented 5- and 6-year-old children and 8- and 9-year-old children in the United States with a story featuring a protagonist in need of help and varied whether the potential helper knew that the protagonist was in need (because the protagonist and potential helper were in the same location) or did not know (because the protagonist and potential help were in different locations). In these cases, we did not find a developmental shift: both younger and older children exhibited discriminate reasoning in that they claimed that knowledgeable others were more obligated to help than unknowledgeable others. 
Such results are consistent with other research finding that young children do make distinctions when considering prosocial obligations outside of social relationships. For example, white children consider other white children more obligated to help a racial in-group than an outgroup, and this does not change with age (Weller \& Lagattuta, 2012; see also, Chalik \& Rhodes, 2020; Pun et al., 2021). Young children also care about whether someone has the capacity to help; children will evaluate someone who is able to help (but does not) more harshly relative to someone who is not able to help (and does not) (Jara-Ettinger, Tenenbaum, \& Schulz, 2015). Together, these findings suggest that young children exhibit discriminant reasoning in some domains, such as groups and capacity, but less so in others, such as social relationships.

\subsection{Concluding remarks}

We want to end on a few limitations. First, adults in our studies were asked to judge whether children are obligated to help one another. Perhaps adults would have considered strangers obligated to help one another if they were adult strangers instead of children. We find this unlikely for a couple of reasons. For one, both the friend and stranger characters were children yet adults judged friends as more obligated to help than strangers; this suggests that it is not the case that adults simply consider children not obligated to help. Second, other research on prosocial obligations with adults that utilized adult strangers in vignettes finds very similar results as the present findings (Earp et al., 2021; Haidt \& Baron, 1996; McManus et al., 2020).

Second, the current work cannot determine whether children and adults consider helping others a moral obligation compared to a social-conventional one (Smetana, 2006). Previous research has differentiated between actions that are a moral obligation-obligations that operate independently from societal rules - and conventional obligations - obligations that are contingent on societal rules. Here, we ask participants to determine whether someone has to help, which only measures an obligation in a broad sense (Kalish \& Lawson, 2008). Consistent with the possibility that the present findings do signify a moral obligation, though, the current results align with previous research that has examined moral obligations specifically, most notably Miller and colleagues (1990) and Dahl and colleagues (2020).

In conclusion, the notion that reasoning about prosocial obligations start off narrow in terms of social relationships and only gradually expand (from kin to friend to stranger) has been held by many philosophers and psychologists - including some of the authors of this current paper (e.g., Bloom, 2013; Wynn et al., 2018). But the findings from our studies support an alternative view. We find that children shift from broad to narrow when it comes to reasoning about prosocial obligations, becoming more selective over the course of development, in a manner qualified by cultural context. 


\section{Acknowledgements}

The authors would like to thank the Mind and Development Lab for helpful feedback on the present studies. We would like to thank the children, parents, schools, and teachers who participated in this research. We would also like to thank the people who helped in the data collection efforts for this project, including Ilona Diewold, Jonathan Kirner, Noerine Kaleeba, Nicholas Sselu, Christine Kaleeba, Thadeus Kasumba, Julius Mpagi, Caroline Atuk, Doreen Twenatween, Alexa Sacchi, Maya Rodriguez, Arianna Hairston, Emily Gerdin, Karli Cecil, Saba Baldiwala, Sakina Dahodwala, and Mahesh Srinivasan. Finally, we would also like to thank two anonymous reviewers for their very helpful feedback, which ultimately substantially improved the manuscript. The work was funded by the Klaus J. Jacobs Research Prize awarded by the Jacobs Foundation. 


\section{References}

Amir, D., \& McAuliffe, K. (2020). Cross-cultural, developmental psychology: Integrating approaches and key insights. Evolution and Human Behavior, 41, 430-444.

Aquinas, T. (1948). Summa theologica. Westminster, MD: Christian Classics.

Axelrod, R. (1987). The evolution of strategies in the iterated prisoner's dilemma. In C. Bicchiere, R. Jeffry, \& B. Skyrms (Eds.), The dynamics of norms (pp. 1-16). New York, NY: Cambridge University Press.

Barragan-Jason, G., Cauchoix, M., Regnier, A., Bourjade, M., Hopfensitz, A., \& Chaine, A. S. (2021). Schoolchildren cooperate more successfully with non-kin than with siblings. Proceedings of the Royal Society B, 288, 20202951.

Barragan, R. C., Brooks, R., \& Meltzoff, A. N. (2020). Altruistic food sharing behavior by human infants after a hunger manipulation. Scientific Reports, 10, 1-9.

Bates, D., Sarkar, D., Bates, M. D., \& Matrix, L. (2007). The lme4 package. $R$ package version, 2, 74.

Bender, A. (2020). The sense of obligation is culturally modulated. Behavioral and Brain Sciences, 43.

Benson, N. J., \& Anglin, J. M. (1987). The child's knowledge of English kin terms. First Language, 7, 41-66.

Blake, P. R., McAuliffe, K., \& Warneken, F. (2014). The developmental origins of fairness: The knowledge-behavior gap. Trends in Cognitive Sciences, 18, 559-561.

Bloom, P. (2013). Just babies: The origins of good and evil. Broadway Books.

Bloom, P. (2011). Family, community, trolley problems, and the crisis in moral psychology. The Yale Review, 99, 26-43.

Brewer, M. B., \& Chen, Y. R. (2007). Where (who) are collectives in collectivism? Toward conceptual clarification of individualism and collectivism. Psychological Review, 114, 133-151.

Callaghan, T., \& Corbit, J. (2018). Early prosocial development across cultures. Current Opinion in Psychology, 20, 102-106.

Chalik, L. \& Rhodes, M. (2020). Groups as moral boundaries: A developmental perspective. In J. Benson (Ed.), Advances in Child Development and Behavior, Volume 58. 
Dahl, A., Gross, R. L., \& Siefert, C. (2020). Young children's judgments and reasoning about prosocial acts: Impermissible, suberogatory, obligatory, or supererogatory?. Cognitive Development. Advanced online copy: https://doi.org/10.1016/j.cogdev.2020.100908

Dahl, A., Waltzer, T. L., \& Gross, R. L. (2018). Helping, hitting, and developing: Toward a constructivist-interactionist account of early morality. In C. C. Helwig (Ed.), New perspectives on moral development. Psychology Press.

Dahl, A. (2019). The science of early moral development: On defining, constructing, and studying morality from birth. Advances in Child Development and Behavior, 56, 1-35.

Dawkins, R. (2016). The selfish gene. Oxford University Press.

DeJesus, J. M., Rhodes, M., \& Kinzler, K. D. (2014). Evaluations versus expectations: Children's divergent beliefs about resource distribution. Cognitive Science, 38, 178-193.

Dunfield, K. A., \& Kuhlmeier, V. A. (2010). Intention-mediated selective helping in infancy. Psychological Science, 21, 523-527.

Dunham, Y., Baron, A. S., \& Banaji, M. R. (2008). The development of implicit intergroup cognition. Trends in Cognitive Sciences, 12, 248-253

Earp, B. D., McLoughlin, K., Monrad, J., Clark, M. S., \& Crockett, M. (2020). How social relationships shape moral judgment. Preprint. https://psyarxiv.com/e7cgq

Engelmann, J., Zhang, Z., Zeidler, H., Dunham, Y., \& Hermann, E. (2021). The influence of friendship and merit on children's resource allocation in three societies. Journal of Experimental Child Psychology, 208.

Engelmann, J., Haux, L., and Hermann, E. (2019). Helping in young children and chimpanzees shows partiality towards friends. Evolution and Human Behavior, 40, 292 300 .

Green, E. G., Deschamps, J. C., \& Paez, D. (2005). Variation of individualism and collectivism within and between 20 countries: A typological analysis. Journal of Cross-Cultural Psychology, 36, 321-339.

Güroğlu, B., van den Bos, W., \& Crone, E. A. (2014). Sharing and giving across adolescence: an experimental study examining the development of prosocial behavior. Frontiers in Psychology, 5, 291.

Haidt, J., \& Baron, J. (1996). Social roles and the moral judgement of acts and omissions. European Journal of Social Psychology, 26, 201-218.

Henrich, J., Ensminger, J., McElreath, R., Barr, A., Barrett, C., Bolyanatz, A., ... \& 
Lesorogol, C. (2010). Markets, religion, community size, and the evolution of fairness and punishment. Science, 327, 1480-1484.

Hester, N., \& Gray, K. (2020). The moral psychology of raceless, genderless strangers. Perspectives on Psychological Science, 15, 216-230.

Hofstede, G. (2011). Dimensionalizing cultures: The Hofstede model in context. Online Readings in Psychology and Culture, 2, 2307-0919.

House, B. R., Kanngiesser, P., Barrett, H. C., Broesch, T., Cebioglu, S., Crittenden, A. N., ... \& Yilmaz, S. (2020a). Universal norm psychology leads to societal diversity in prosocial behaviour and development. Nature Human Behaviour, 4, 36-44.

House, B. R., Silk, J. B., Henrich, J., Barrett, H. C., Scelza, B. A., Boyette, A. H., ... \& Laurence, S. (2013). Ontogeny of prosocial behavior across diverse societies. Proceedings of the National Academy of Sciences, 110, 14586-14591.

Jara-Ettinger, J., Tenenbaum, J. B., \& Schulz, L. E. (2015). Not so innocent: Toddlers' inferences about costs and culpability. Psychological Science, 26, 633-640.

Jeske, D. (1998). Families, friends, and special obligations. Canadian Journal of Philosophy, 28, $527-555$.

Kalish, C. W., \& Lawson, C. A. (2008). Development of social category representations: Early appreciation of roles and deontic relations. Child Development, 79, 577-593.

Kapoor, S., Hughes, P. C., Baldwin, J. R., \& Blue, J. (2003). The relationship of individualismcollectivism and self-construals to communication styles in India and the United States. International Journal of Intercultural Relations, 27, 683-700.

Lenz, S., \& Paulus, M. (2021). Friendship is more than strategic reciprocity: Preschoolers' selective sharing with friends cannot be reduced to strategic concerns. Journal of Experimental Child Psychology, 206, 105101.

Li, X., Wu, X., Hou, M., Zeng, M., Jiang, N., \& Zhang, J. (2021). Effects of peer relationship and peer presence on giving and repaying in preschoolers' triad interactions. PsyCh Journal.

Lu, H. J., \& Chang, L. (2016). Resource allocation to kin, friends, and strangers by 3-to 6-yearold children. Journal of Experimental Child Psychology, 150, 194-206.

Maccoby, E. E. (2007). Historical overview of socialization research and theory. In J. E. Grusec \& P. D. Hastings (Eds.), Handbook of socialization: Theory and research (pp. 13-41). New York, NY: Guilford Press.

Mammen, M., Köymen, B., \& Tomasello, M. Young children's moral judgments depend on the social relationship between agents. Cognitive Development, 57, 100973. 
Marshall, J., Mermin-Bunnell, K., \& Bloom, P. (2020). Developing judgments about peers' obligation to intervene. Cognition, 201.

Marshall, J., Wynn, K., \& Bloom, P. (2020). Do children and adults take social relationship into account when evaluating people's actions?. Child Development, 91, 1082-1100.

McManus, R. M., Mason, J. E., \& Young, L. (2021). Re-examining the role of family relationships in structuring perceived helping obligations, and their impact on moral evaluation. Journal of Experimental Social Psychology, 96, 104182.

McManus, R. M., Kleiman-Weiner, M., \& Young, L. (2020). What we owe to family: The impact of special obligations on moral judgment. Psychological Science, 31, 227-242.

Mende-Siedlecki, P., Baron, S. G., \& Todorov, A. (2013). Diagnostic value underlies asymmetric updating of impressions in the morality and ability domains. Journal of Neuroscience, 33, 19406-19415.

Miller, J. G., Bersoff, D. M., \& Harwood, R. L. (1990). Perceptions of social responsibilities in India and in the United States: Moral imperatives or personal decisions?. Journal of Personality and Social Psychology, 58, 33-47.

Moore, C. (2009). Fairness in children's resource allocation depends on the recipient. Psychological Science, 20, 944-948.

Muthukrishna, M., Bell, A. V., Henrich, J., Curtin, C. M., Gedranovich, A., McInerney, J., \& Thue, B. (2020). Beyond Western, Educated, Industrial, Rich, and Democratic (WEIRD) psychology: Measuring and mapping scales of cultural and psychological distance. Psychological Science, 31, 678-701.

Narveson, J. (2017). Feeding the Hungry. Applied Ethics: A Multicultural Approach, 142-148.

Nielsen, M., \& Haun, D. (2016). Why developmental psychology is incomplete without comparative and cross-cultural perspectives. Philosophical Transactions of the Royal Society B: Biological Sciences, 371, 20150071.

Nielsen, M., Haun, D., Kärtner, J., \& Legare, C. H. (2017). The persistent sampling bias in developmental psychology: A call to action. Journal of Experimental Child Psychology, 162, 31-38.

Olson, K. R., \& Spelke, E. S. (2008). Foundations of cooperation in young children. Cognition, 108, 222-231.

Ogihara, Y. (2017). Temporal changes in individualism and their ramification in Japan: rising individualism and conflicts with persisting collectivism. Frontiers in Psychology, 8, 695. 
Paulus, M., Christner, N., \& Wörle, M. (2020). The normative status of friendship: Do young children enforce sharing with friends and appreciate reasonable partiality?. Journal of Experimental Child Psychology, 194, 104826.

Paulus, M., \& Moore, C. (2014). The development of recipient-dependent sharing behavior and sharing expectations in preschool children. Developmental Psychology, 50, 914-921.

Pratt, M. W., \& Hardy, S. A. (2014). Cultivating the moral personality: Socializing in the family and beyond. In J. E. Grusec \& P. D. Hastings (Eds.), Handbook of socialization (2nd ed., pp. 661-685). New York: Guilford Press.

Pun, A., Birch, S. A., \& Baron, A. S. (2021). The power of allies: Infants' expectations of social obligations during intergroup conflict. Cognition, 211, 104630.

Raabe, T., \& Beelmann, A. (2011). Development of ethnic, racial, and national prejudice in childhood and adolescence: A multinational meta-analysis of age differences. Child Development, 82, 1715-1737.

Rarick, C., Winter, G., Nickerson, I., Falk, G., Barczyk, C., \& Asea, P. K. (2013). An investigation of Ugandan cultural values and implications for managerial behavior. Global Journal of Management and Business Research.

Rao, N., \& Stewart, S. M. (1999). Cultural influences on sharer and recipient behavior: Sharing in Chinese and Indian preschool children. Journal of Cross-Cultural Psychology, 30, 219 241.

Rhodes, M., \& Wellman, H. (2017). Moral learning as intuitive theory revision. Cognition, 167, 191-200.

Scharpf, F., Paulus, M., \& Wörle, M. (2017). The impact of social relationships on Ugandan children's sharing decisions. European Journal of Developmental Psychology, 14, 436448.

Schein, C. (2020). The importance of context in moral judgments. Perspectives on Psychological Science, 15, 207-215.

Singer, P. (1981). The expanding circle. Oxford: Clarendon Press.

Smetana, J. G. (2006). Social domain theory: Consistencies and variations in children's moral and social judgments. In M. Killen, \& J. G. Smetana (Eds.). Handbook of moral development (pp. 119-153). Mahwah, NJ: Erlbaum.

Sommers, C. H. (1986). Filial morality. The Journal of Philosophy, 83, 439-456.

Spokes, A. C., \& Spelke, E. S. (2016). Children's expectations and understanding of kinship as a social category. Frontiers in Psychology, 7, 440. 
Takano, Y., \& Osaka, E. (2018). Comparing Japan and the United States on individualism/collectivism: A follow-up review. Asian Journal of Social Psychology, 21, 301-316.

Tomasello, M. (2020). The moral psychology of obligation. Behavioral and Brain Sciences, 43, 1-58.

Turiel, E. (2015). Morality and prosocial judgments and behavior. In D. A. Schroeder \& W. G. Graziano (Eds.), The Oxford handbook of prosocial behavior (pp. 137-152). Oxford, UK: Oxford University Press.

Turiel, E. (1983). The development of social knowledge: Morality and convention. Cambridge, UK: Cambridge University Press.

Vonk, J., Jett, S. E., Tomeny, T. S., Mercer, S. H., \& Cwikla, J. (2020). Young children's theory of mind predicts more sharing with friends over time. Child Development, 91, 63-77.

Yamawaki, N. (2012). Within-culture variations of collectivism in Japan. Journal of CrossCultural Psychology, 43, 1191-1204.

Yu, H., Siegel, J. Z., \& Crockett, M. J. (2019). Modeling Morality in 3-D: Decision-Making, Judgment, and Inference. Topics in Cognitive Science, 11, 409-432.

Yu, J., Zhu, L., \& Leslie, A. M. (2016). Children's sharing behavior in mini-dictator games: The role of in-group favoritism and theory of mind. Child Development, 87, 1747-1757.

Warneken, F., \& Tomasello, M. (2009). The roots of human altruism. British Journal of Psychology, 100, 455-471.

Weller, D., \& Hansen Lagattuta, K. (2013). Helping the in-group feels better: Children's judgments and emotion attributions in response to prosocial dilemmas. Child Development, 84, 253-268.

Wynn, K., Bloom, P., Jordan, A., Marshall, J., \& Sheskin, M. (2018). Not noble savages after all: Limits to early altruism. Current Directions in Psychological Science, 27, 3-8.

Wynn, K. (2009). Constraints on natural altruism. British Journal of Psychology, 100, 481-485. 